\title{
Butanol production from lignocellulosic biomass: revisiting fermentation performance indicators with exploratory data analysis
}

\author{
Cansu Birgen ${ }^{1 *} \mathbb{B}$, Peter Dürre ${ }^{2}$, Heinz A. Preisig ${ }^{1}$ and Alexander Wentzel ${ }^{3}$
}

\begin{abstract}
After just more than 100 years of history of industrial acetone-butanol-ethanol (ABE) fermentation, patented by Weizmann in the UK in 1915, butanol is again today considered a promising biofuel alternative based on several advantages compared to the more established biofuels ethanol and methanol. Large-scale fermentative production of butanol, however, still suffers from high substrate cost and low product titers and selectivity. There have been great advances the last decades to tackle these problems. However, understanding the fermentation process variables and their interconnectedness with a holistic view of the current scientific state-of-the-art is lacking to a great extent. To illustrate the benefits of such a comprehensive approach, we have developed a dataset by collecting data from 175 fermentations of lignocellulosic biomass and mixed sugars to produce butanol that reported during the past three decades of scientific literature and performed an exploratory data analysis to map current trends and bottlenecks. This review presents the results of this exploratory data analysis as well as main features of fermentative butanol production from lignocellulosic biomass with a focus on performance indicators as a useful tool to guide further research and development in the field towards more profitable butanol manufacturing for biofuel applications in the future.
\end{abstract}

Keywords: Butanol, Clostridia, ABE fermentation, Lignocellulosic biomass, Mixed sugars, Exploratory data analysis

\section{Introduction}

Chemicals and fuels from renewable resources have gained global interest due to rising global warming and climate change concerns, volatility of oil price and supply, and legal restrictions on nonrenewable energy sources [1]. $n$-Butanol (in the further run for simplicity reasons referred to as butanol) is a promising biofuel alternative based on several advantages compared to the more established biofuels ethanol and methanol: a longer carbon chain length and thus a higher heating value, as well as lower volatility, polarity, corrosivity and heat of vaporization, leading to lesser ignition problems. Moreover, diesel engines can run on pure butanol or diesel blends without any modifications and apparent damage [2]. A more detailed overview of the physical properties of butanol in

\footnotetext{
*Correspondence: cansu.birgen@ntnu.no

${ }^{1}$ Department of Chemical Engineering, NTNU, 7491 Trondheim, Norway

Full list of author information is available at the end of the article
}

comparison to other biofuels, gasoline and diesel can be found elsewhere in literature [3, 4].

\section{A brief history of biological butanol production}

Biological production of butanol under anaerobic conditions is typically referred to in literature as a part of 'ABE fermentation', since acetone, butanol and ethanol are usually produced simultaneously in this process. Louis Pasteur was the first to report about microbial butanol production in 1862 [5]. However, the first production utilizing the Weizmann process began only in 1913, aiming to produce acetone for rubber synthesis [6]. Later in 1916, the first industrial-scale ABE fermentation began operation due to a high demand for acetone during World War I, and after the armistice in November 1918, most of the plants were shut down [7].

Industrial $\mathrm{ABE}$ fermentation, however, kept expanding worldwide, facilitated by the usability of butanol as a solvent [6]. In 1945, two-thirds of the butanol and onetenth of the acetone in the U.S. were produced by $\mathrm{ABE}$ 
fermentation processes. However, their share in the total output declined rapidly during the 1950s mainly because of the acute competition with the expanding petrochemical industry and decreasing feedstock availability [8]. ABE fermentation became popular again in the 1970s after the oil crisis, and it has since been gaining increasing interest owing to the advancements in Metabolic Flux Analysis (1984), Metabolic Engineering (1992), Gene KO Homologous Recombination (1994), and Complete Genome Sequencing (2001) [7], holding promise of improved production yields and productivities for more economic microbial production processes. There are several excellent reviews covering the historical development of $A B E$ fermentation in detail $[6,7,9-11]$.

\section{Previous reviews covering the topic}

There are several challenges such as high substrate cost, solvent toxicity, low cell density and by-product formation that need to be addressed for sustainable and economical fermentative butanol production. These issues cause low butanol yield, titer, productivity and selectivity.

Great efforts have been made to find cheap/free feedstock and cost efficient processing methods to overcome the high substrate cost problem, and several review papers address this issue in detail [3, 12-18]. Low solvent tolerance limits the butanol titer to maximum $2 \%$ dependent of the strain used [19], causing high downstream processing cost; therefore some reviews collected and discuss information on this specific challenge [20, 21]. Efficient separation of butanol from the fermentation mixture is another important topic with several reviews discussing particularly downstream processes for $A B E$ fermentation [3, 22]. Strain improvement by metabolic engineering has an important role in optimizing butanol production. For details, readers can refer to "Strain development" section below, as well as the review papers published on the features of clostridial pathways and metabolic engineering of butanol producers [23-31].

Main issues and possible solutions discussed in previous review papers are summarized in Table 1 that provides a comprehensive overview in terms of their frequency of appearance.

\section{The aim and scope of the present review}

The aim of the present review is to provide a critical overview of existing literature on fermentative butanol

Table 1 Summary of main challenges and solutions for fermentative butanol production

\begin{tabular}{|c|c|}
\hline Challenge & Suggested solution \\
\hline High substrate cost & $\begin{array}{l}\text { Lignocellulosic substrates }[3,12-15,18,23,29,31-35] \\
\text { Starch based waste }[12,29,33] \\
\text { Syngas }[12,23,24,33,35] \\
\text { Macroalgae }[12,16,23] \\
\text { Crude glycerol }[12,23,24,31] \\
\text { Protein waste }[23] \\
\text { Whey permeate }[14,29,34] \\
\text { Economical feedstock processing methods }[3,18,29] \\
\text { Medium optimization }[18,28] \\
\text { Inulin }[31]\end{array}$ \\
\hline Low butanol selectivity & $\begin{array}{l}\text { Metabolic engineering for disruption of the pathway for acetone }[3,13-15,23,25,27,32,34] \\
\text { Homo-butanol fermentation via chemical mutagenesis and metabolic engineering }[23,24,33,35] \\
\text { Conversion of acetone into isopropanol }[13,15,23] \\
\text { Decoupling sporulation from solventogenesis }[3,13,14,23,25,27,28,34,35]\end{array}$ \\
\hline Low butanol titer & $\begin{array}{l}\text { Metabolic engineering and mutagenesis for higher butanol tolerance }[13-15,21,23-25,27,28,32-35] \\
\text { In situ product removal }[3,12-15,18,22,23,27,28,32,34,35] \\
\text { Introducing butanol pathways in other hosts }[3,13,15,21,23-25,27,33-35] \\
\text { Re-enforcing hot channel for butanol formation }[14]\end{array}$ \\
\hline Low butanol yield & $\begin{array}{l}\text { Simultaneous utilization of mixed sugars in the hydrolysate without Carbon Catabolite Repression }[14,23,31] \\
\text { Extending the substrate utilization range }[15,34,35]\end{array}$ \\
\hline Low butanol productivity & $\begin{array}{l}\text { Simultaneous utilization of mixed sugars without Carbon Catabolite Repression }[3,23,28,29] \\
\text { Fed-batch fermentation }[3,12,14,18,34] \\
\text { Chemostat/continuous culturing }[3,12-15,18,32,34] \\
\text { Immobilized cell chemostat }[3,12-15,18,34] \\
\text { Cell recycle chemostat }[3,12-15,18,34] \\
\text { Multi stage chemostat }[3,13,14,18]\end{array}$ \\
\hline Low $\mathrm{O}_{2}$ tolerance & $\begin{array}{l}\text { Co-culturing to maintain anaerobic conditions [32] } \\
\text { Random mutagenesis and selection }[13,35] \\
\text { Metabolic engineering }[27,36]\end{array}$ \\
\hline Culture degeneration & Prevention of excessive acidification of the culture [35] \\
\hline Phage contamination & Good factory hygiene, strains immune to specific phages $[27,35]$ \\
\hline
\end{tabular}


production from lignocellulosic biomass and mixed sugars in batch mode with a focus on performance indicators. A comprehensive collection of data derived from original literature of the last 3 decades thereby laid the basis for performing exploratory data analysis (EDA).

\section{Fermentative butanol production from lignocellulosic biomass}

A typical conversion process from lignocellulosic biomass to butanol involves three major steps: pretreatment, detoxification and fermentation. A representative schematic diagram of the process is shown in Fig. 1.

\section{Pretreatment}

Lignocellulosic biomass is a favorable feedstock since it is the most abundant renewable biomass resource on the planet, and, compared to sugars from e.g. sugar cane or maize, it avoids direct fuel-versus-food competition. It is the feedstock for butanol production suggested most frequently in literature as shown in Table 1. Its main constituents are cellulose, hemicellulose and lignin [37]. The opening of the lignocellulosic biomass structure and the release of sugar content from hemicellulose and cellulose with other cross-linked units and the residual non-hydrolyzed raw feedstock is called pretreatment [38]. Conversion of biomass into its main constituents is referred to in literature as fractionation, which is sometimes used interchangeably with pretreatment, i.e. pretreatment is mentioned as a way of achieving biomass fractionation, or the term fractionation is used as (part of) a pretreatment method $[13,39,40]$. In the present study, for simplicity reasons we name all steps involved in the conversion of the feedstock to sugars as pretreatment though enzymatic hydrolysis of the polysaccharide fractions is often referred to as a step that is distinct from other pretreatment measures. Predominance of enzymatic hydrolysis in the pretreatment methods in Fig. 2a shows its

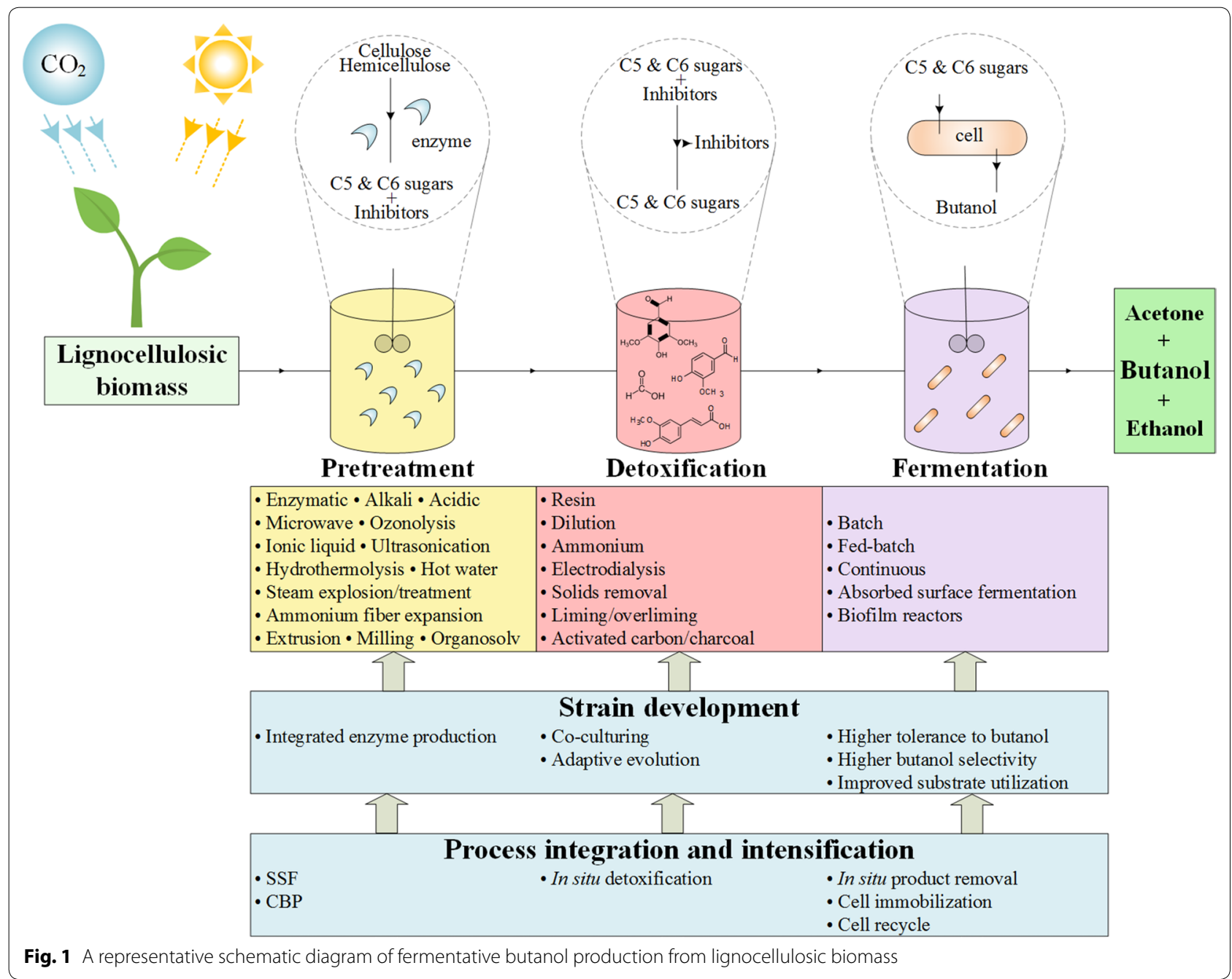




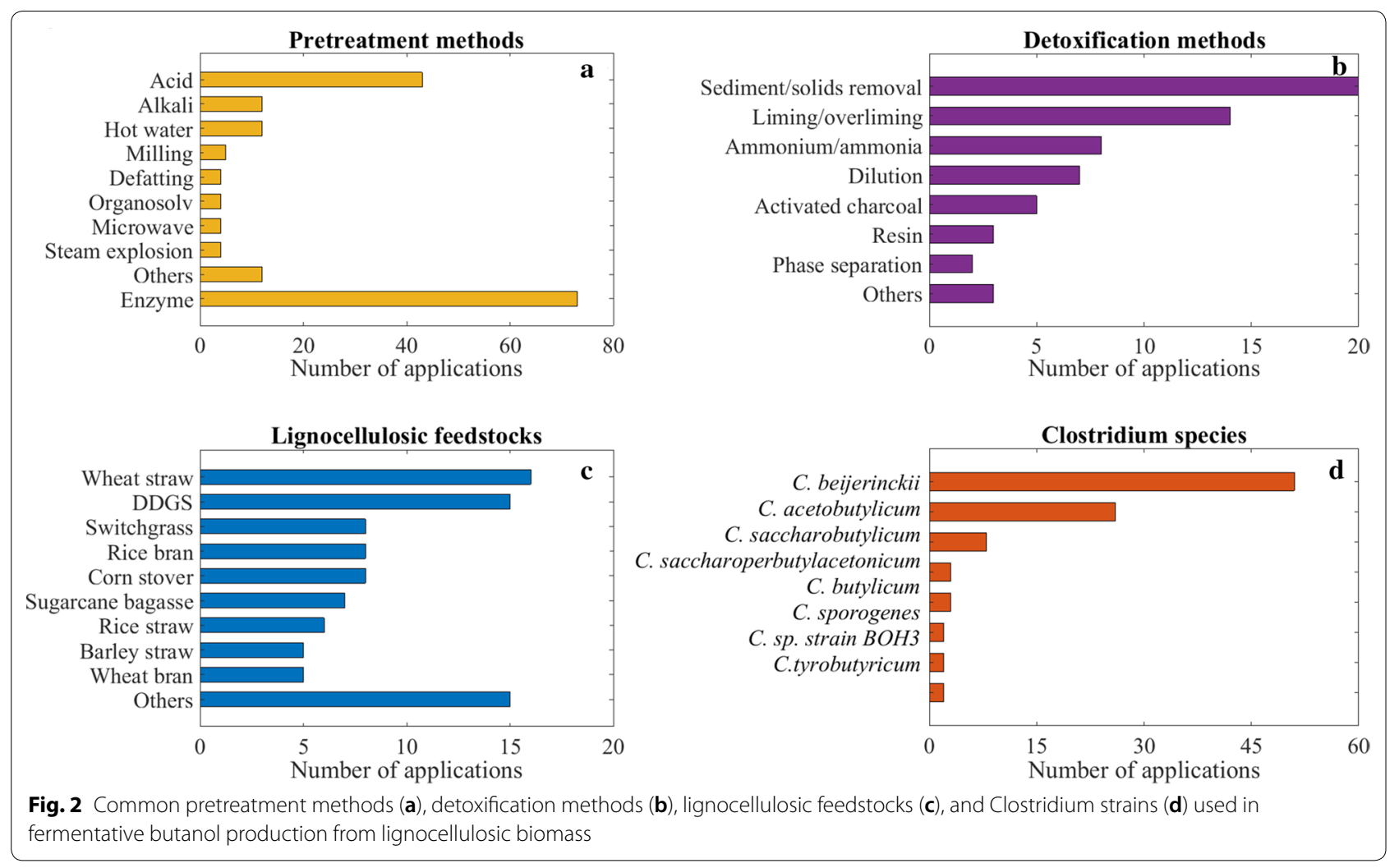

widespread application to produce fermentable sugars from lignocellulosic biomass.

Milling/grinding, extrusion, microwave and ultrasonication are common physical pretreatment methods that open up the physical structure of lignocellulosic biomass [41-47]. Physico-chemical methods such as steam explosion, steam treatment, hydrothermolysis, ammonium fiber expansion, and hot water treatment cause both the structure to unravel and a release of sugar monomers and dimers [42, 48-52]. Major chemical pretreatment methods are alkali, acidic, ozonolysis, ionic liquid and organosolv treatments [41-44, 48-73].

Enzymatic hydrolysis using suitable enzyme mixtures degrades polysaccharides such as cellulose and xylan to fermentable C6 and C5 sugar monomers, respectively [74]. Typically, combinations of several of the above-mentioned pretreatment methods are employed depending on the feedstock. Operating conditions of pretreatment are crucial since a small change in the operating parameters can cause great differences in reduced sugar composition and concentration as well as inhibitory compounds, consequently negatively affecting enzymatic hydrolysis, fermentability and the cost of substrate [18]. Therefore, it is crucial to examine the feasibility of any pretreatment method with respect to the generation of inhibitors, energy consumption, operating cost, and sugar yield.

\section{Detoxification}

Compounds that are inhibitory to microorganisms and enzymes are often generated during pretreatment [74]. Cellulose and hemicellulose should ideally only yield sugar monomers such as glucose, xylose, and mannose. However, severity of some pretreatment conditions converts those sugars into furfural, 5-hydroxymethyl furfural (HMF), formic acid, acetic acid, levulinic acid and salts, which can be inhibitory $[18,75]$. Partial decomposition of lignin generates inhibitory (poly)phenolic aromatic compounds such as $p$-coumaric acid, ferulic acid, syringe aldehyde, vanillic acid and vanillin [18]. Contrary to ethanol-producing microorganisms like the yeast $\mathrm{Sac}$ charomyces cerevisiae, furfural, HMF or acetic acid are not inhibitory to clostridial butanol producers at relatively low concentrations, rather they are reported to be stimulatory [76]. Another common compound generated during pretreatment of lignocellulosic biomass is formic acid. It is found to be inhibitory to $C$. acetobutylicum at $0.5 \mathrm{~g} / \mathrm{l}$ [77] and $0.074 \mathrm{~g} / \mathrm{l}(1 \mathrm{mM})$ inside the cell wall [78] due to acid crash [79]. Therefore, if larger amounts of inhibitors are present after pretreatment, it is a necessity 
to remove these for a successful fermentation. For this purpose, several detoxification methods such as electrodialysis [66], liming/overliming [48, 49, 57-59, 73], activated carbon/charcoal [50,51, 71, 72], dilution [44, 66], and resin treatments $[54,63]$ are applied. Even though it is not specifically mentioned as a detoxification method, solid/sediment removal by filtration or centrifugation is also commonly applied to alleviate the inhibitory effects of the solids and undissolved lignin in the lignocellulosic hydrolysates $[41,53,54,59,63,66]$. It is important to note that the enzymes used in the hydrolysis step can be inhibited by the compounds mentioned above as well as their sugar yields, which can impose a limit to high substrate concentration [74]. Alternative lines of research currently target new pretreatment methods that are less prone to inhibitor formation (like organosolv or other low-temperature methods) and thus ideally do not require detoxification prior to fermentation, as well as increasing the inhibitor tolerance of fermentation strains e.g. by means of adaptive evolution.

\section{Fermentation}

$\mathrm{ABE}$ fermentation is biphasic; first, acetic acid and butyric acid are produced in the acidogenesis phase, then the acids are re-assimilated to yield the solvents acetone, butanol and ethanol [80]. Batch fermentation is the most studied mode due to simple operation and low risk of contamination [81], and readers can access numerous original studies of batch fermentations of lignocellulosic biomass to produce butanol [41-44, 48-73]. Low cell density can result in low productivity, and absorbed substrate fermentation [82] and biofilm reactors [83] have been applied to overcome this problem in batch processes. Fed-batch mode is beneficial to tackle substrate inhibition by gradually adding the substrate, thus keeping the substrate concentration below toxic levels [84]. However, fed-batch fermentation should still be accompanied by in situ product removal to alleviate product inhibition [60, 85, 86]. Continuous fermentation (chemostat) has advantages over batch and fed-batch modes such as improved productivity [84]. Multi-stage [87], immobilized cell $[88,89]$, cell recycling and bleeding [90, 91] techniques have been applied to improve chemostat performance.

\section{Strain development}

Strain development refers to any modifications in the butanol production strain done by random mutagenesis and selection, like in adaptive laboratory evolution, or directed, rational and/or systems biology guided genetic modification employing metabolic engineering and synthetic biology to improve fermentation performance by means of increased tolerance to toxic components, butanol selectivity and productivity, and improved substrate utilization and range.

In general, detoxification methods shown in Fig. 2a are used for removal of inhibitors present in the substrate and/or feedstock as described in "Detoxification" section. Co-culturing with other species to eliminate toxic components such as oxygen in case of anaerobic fermentation is an alternative method [32]. Random mutagenesis and selection [13, 35], and metabolic engineering [27, 36] have been applied for the same purpose. Inhibition due to butanol accumulation is one of the greatest challenges. Therefore, metabolic engineering and mutagenesis have been targeting this specific problem as well by developing strains with greater to resistance to butanol toxicity [13-15, 21, 23-25, 27, 28, 32-35].

A typical fermentative butanol production yields acetone and ethanol as well, which decreases the selectivity of the product of interest. Metabolic engineering for disruption of acetone producing pathways [92], homo-butanol fermentation via chemical mutagenesis and metabolic engineering and conversion of acetone into isopropanol are among the strategies developed to address this issue.

Efficient utilization of the substrate is crucial to achieve a high butanol yield, thus improving fermentation performance [14, 23, 31]. Disrupting the genes responsible for Carbon Catabolite Repression and overexpression of genes responsible for xylose transport and catalytic enzymes (D-xylose isomerase, xylulokinase, and enzymes of PPP) are commonly followed approaches [71, 72, 93, 94].

It is important to mention the recent efforts on CRISPR-Cas9 genome engineering systems to improve butanol production by fermentation. Most of the research focuses on production by Escherichia coli [95]. However, Clostridial butanol production improvements have been achieved by using this technique as well [96].

In summary, the increasing numbers of publications in recent years employing strain engineering techniques and approaches to address key bottlenecks in clostridial butanol production hold promise to finally solving these in the future.

\section{Process integration and intensification}

Process integration and intensification techniques are applied to obtain cost-effective fermentation processes. Important process intensification approaches include (a) simultaneous saccharification and (co-)fermentation (SSF or SSCF) in which hydrolysis of polysaccharides present in (pre-treated) biomass is performed by externally produced and added hydrolytic enzyme mixes in situ with the simultaneous fermentation of the liberated sugars by a strain (or in the case of SSCF several strains with 
complementary sugar substrate spectrum) producing the product of choice, e.g. butanol [42, 53], and (b) consolidated bioprocessing (CBP) in which the saccharolytic enzymes are produced within the sugar fermenting culture e.g. by the target product producing strain itself or in co-culture with a partner strain specialized in enzyme production and secretion [97].

Gas stripping, pervaporation, adsorption, liquid-liquid extraction, pertraction (membrane extraction), reverse osmosis and membrane distillation are in situ product removal methods used to alleviate inhibitory effects of butanol $[3,22]$. Fermentation with integrated gas stripping has widely been studied, mostly in fed-batch mode, which showed improved butanol productivity $[60,85]$.

Cell immobilization and cell recycle are mostly integrated to fermenters operated in continuous mode to improve butanol productivity by preventing the loss of cell mass with the bleeding stream out from the fermenter.

Process integration and intensification measures therefore play crucial roles in optimizing butanol fermentation processes for improved performance and economic competitiveness.

\section{Fermentative butanol production from mixed sugars}

There has been a great scientific interest in the utilization of different sugars in mixed form for the production of biofuels, since pre-processed lignocellulosic biomass feedstock usually contains a mixture of pentoses (C5) such as xylose and arabinose, and hexoses (C6) such as glucose and mannose. Therefore, efficient utilization of C5 and C6 sugars is a prerequisite for a successful fermentation process with optimized carbon utilization. In this section, we review the studies focusing on clostridial mixed sugar fermentations producing butanol.

Mixed sugar fermentation studies date back to early 1980 s, in which the researchers investigated the influence of different pentose and hexose sugars and their mixtures at different ratios on the fermentation kinetics [98]. Some clostridia have shown to readily consume sugar mixtures; however, they do so with poor efficiency [99]. Even though both strains can utilize glucose and xylose, C. beijerinckii has a large gene cluster containing most of the genes involved in xylose metabolism and regulation, while in $C$. acetobutylicum the xylose-related genes are dispersed over several different chromosomal locations [100]. Moreover, C. beijerinckii has more sets of xylose metabolic pathway genes than $C$. acetobutylicum [101]. Cells' efficiency of simultaneously using sugars in mixed form decreases due to a phenomenon called carbon catabolite repression (CCR). Consequently, utilization of pentose sugars is reduced or prevented entirely in the presence of a preferred sugar such as glucose [94]. Furthermore, CCR can cause sequential utilization of sugars (diauxic growth) and a lag phase, which increases the residence time, thus operating costs. There have been attempts to improve product titers by using immobilized cultures [102], optimizing the culture $\mathrm{pH}$ and glucose to xylose ratio [103] and adding nutritional supplements [104] for fermentative butanol production from mixed sugars. In addition, genomic information [101, 105, 106] and transcriptome analysis results [107-112] of lignocellulosic sugar metabolisms and respective repression mechanisms are available in the literature.

There is ongoing research on metabolic engineering to develop clostridial strains capable of simultaneously fermenting hexose and pentose for butanol production [71, 93, 94, 113, 114]. Even though Lee et al. [23] stated metabolic engineering is necessary for simultaneous utilization of sugars, researchers have developed different feeding and pre-growth strategies achieving co-utilization without any strain manipulation [73, 115-120]. However, in the mixed sugar fermentation study of Zhang et al. [121], transcriptional studies suggested that glucose inhibition on xylose metabolism-related genes was still present despite the simultaneous utilization of glucose and xylose.

\section{Dataset development and exploratory data analysis for fermentative butanol production from lignocellulosic biomass and mixed sugars}

By reviewing and extracting information from original research articles on clostridial fermentative batch production of butanol from lignocellulosic biomass and mixed sugars during the last three decades, we have developed a comprehensive dataset. 77 lignocellulosic hydrolysate, 19 lignocellulosic hydrolysate with additional glucose, and 79 mixed sugars fermentations have been included in the dataset, covering 175 fermentations in total. The dataset contains reported initial and final concentrations of all sugars and other components found in the substrates, all reported products in the fermentation broth, fermentation time, clostridial strain type, feedstock type, pretreatment method, and detoxification method used for those 175 fermentations. Latter four are summarized in Fig. 2 to illustrate their application frequencies. All the fermentations included in the dataset were conducted in batch mode. Quantification of fermentation products and substrates were done by using high pressure liquid chromatography and gas chromatography. As far as reported, data were directly derived from the article texts and tables, otherwise we used the WebPlotDigitizer tool [122] for mining the information from the plots. The dataset can be found in Additional file 1. 
EDA is a statistical approach to analyze datasets for summarizing their main characteristics, which was promoted by John Tukey to encourage statisticians for in depth data exploration [123]. We used boxplot as a visual tool for EDA, which is a graphical method for illustration of numerical data groups through their quartiles that is the middle number between the smallest number and the median of the dataset. The lines extending vertically from the boxes called whiskers indicate the variability outside the upper and lower quartiles. In Figs. 4, 5, 6, boxplots are represented as rectangles with a vertical line showing the mean value, whiskers shown as dashed lines, and outliers are individual plus signs. We used built-in Matlab function to construct the boxplots.

22 fermentation variables from 175 fermentations were selected for EDA due to their importance for the process. Definitions and explanations of the fermentation variables can be found in "Substrate properties", "Product mixture properties" and "Performance indicators" sections together with the results of EDA. It is important to note that the dataset could only include what was reported in the papers; there is therefore a possibility of unreported, unidentified and undetected components in the hydrolysates affecting production results and performance indicators.

\section{Substrate properties}

In lignocellulosic substrate fermentation, the hydrolysate represents the sole source of carbon; however, microorganisms also need other nutrients such as nitrogen, phosphorous, sulfur, vitamins and minerals for growth and production. Typically, P2 stock solution and yeast extract are added externally, which increases the substrate cost [41-44, 48-73]. To tackle this problem, there have been attempts to provide the essential nutrients from waste materials such as wastewater sludge [55]. Optimization of medium components to minimize the substrate cost is important to consider when designing a fermentation process [18]. As discussed earlier, substrate composition has a great influence on fermentation; therefore, average amounts of 12 different components found in hydrolysates of 17 different lignocellulosic feedstock are shown in Fig. 3.

Figure 3 shows that glucose and xylose were the most commonly found sugar monomers in lignocellulosic hydrolysates. Therefore, initial concentrations (g/l) of these two sugars were selected as fermentation variables for EDA together with the total sugar concentration $(\mathrm{g} / \mathrm{l})$. We chose glucose ratio (glucose concentration/total sugar concentration $\times 100 \%$ ) and xylose ratio (xylose concentration/total sugar concentration $\times 100 \%$ ) as fermentation variables as well as initial acetic acid concentration $(\mathrm{g} / \mathrm{l})$ since it is often produced during pretreatment and

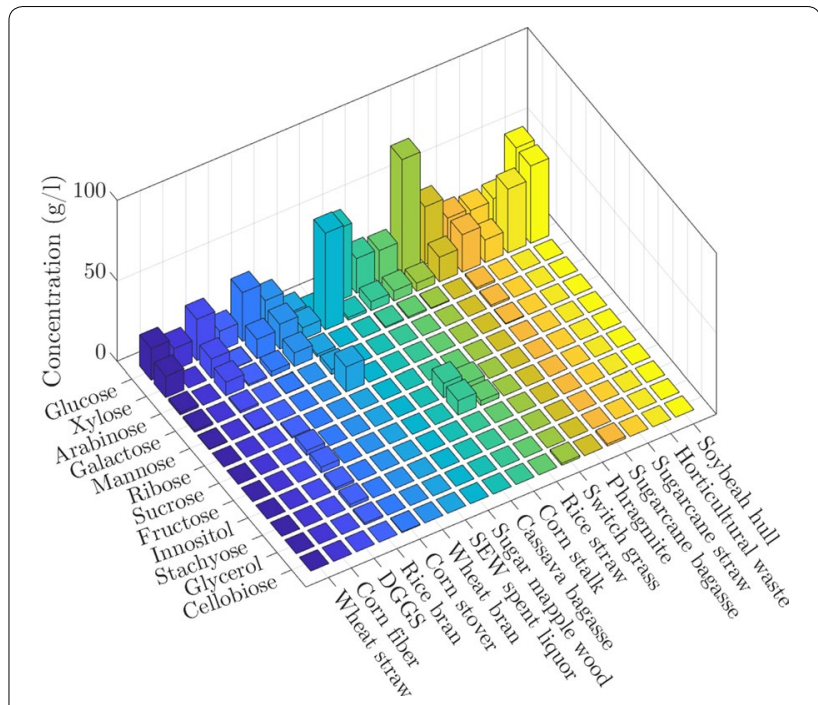

Fig. 3 Concentrations of substrate components present in the lignocellulosic hydrolysates

has substantial effects on fermentation [101]. Thus, we identified 6 fermentation variables in total for EDA to investigate substrate properties as shown in Fig. 4.

In Fig. 4, initial concentrations of total substrates and their common constituents glucose, xylose, acetic acid as well as glucose and xylose ratios are shown for lignocellulosic hydrolysate, lignocellulosic hydrolysate with glucose, and mixed sugar fermentations.

For lignocellulosic hydrolysates, the medians of total sugars, glucose, xylose and initial acetic acid concentrations were 41.8, 23.6, 10.8 and 2.5 g/l, respectively. Outliers worth to mention include soybean hull hydrolysis yielding $49 \mathrm{~g} / \mathrm{l}$ glucose and $48 \mathrm{~g} / \mathrm{l}$ xylose [72], switchgrass yielding $77 \mathrm{~g} / \mathrm{l}$ glucose with total sugar of $82 \mathrm{~g} / \mathrm{l}$ [51], horticultural waste with $6 \mathrm{~g} / \mathrm{l}$ glucose and $58 \mathrm{~g} / \mathrm{l}$ xylose [71], and sugarcane bagasse containing $15 \mathrm{~g} / \mathrm{l}$ glucose and $44 \mathrm{~g} / \mathrm{l}$ xylose [42]. The deviation from the general trend could be due to the feedstock properties as well as the specific pretreatment methods.

Addition of glucose to the hydrolysate is a common practice to increase the total sugar concentration in the fermentation medium. Therefore, the total and individual sugar concentrations were higher for lignocellulosic hydrolysates with glucose. The medians of total sugar, glucose, and xylose concentrations were 60.05, 40.4, and 15.7 , respectively. Glucose was occasionally added to wheat straw hydrolysate incrementally until the microorganisms were inhibited due to high substrate concentration [41], which resulted in outliers in Fig. 4b together with a case where glucose was added to cassava bagasse hydrolysate [60]. It is important to mention the change in glucose and xylose ratios due to addition of glucose. 

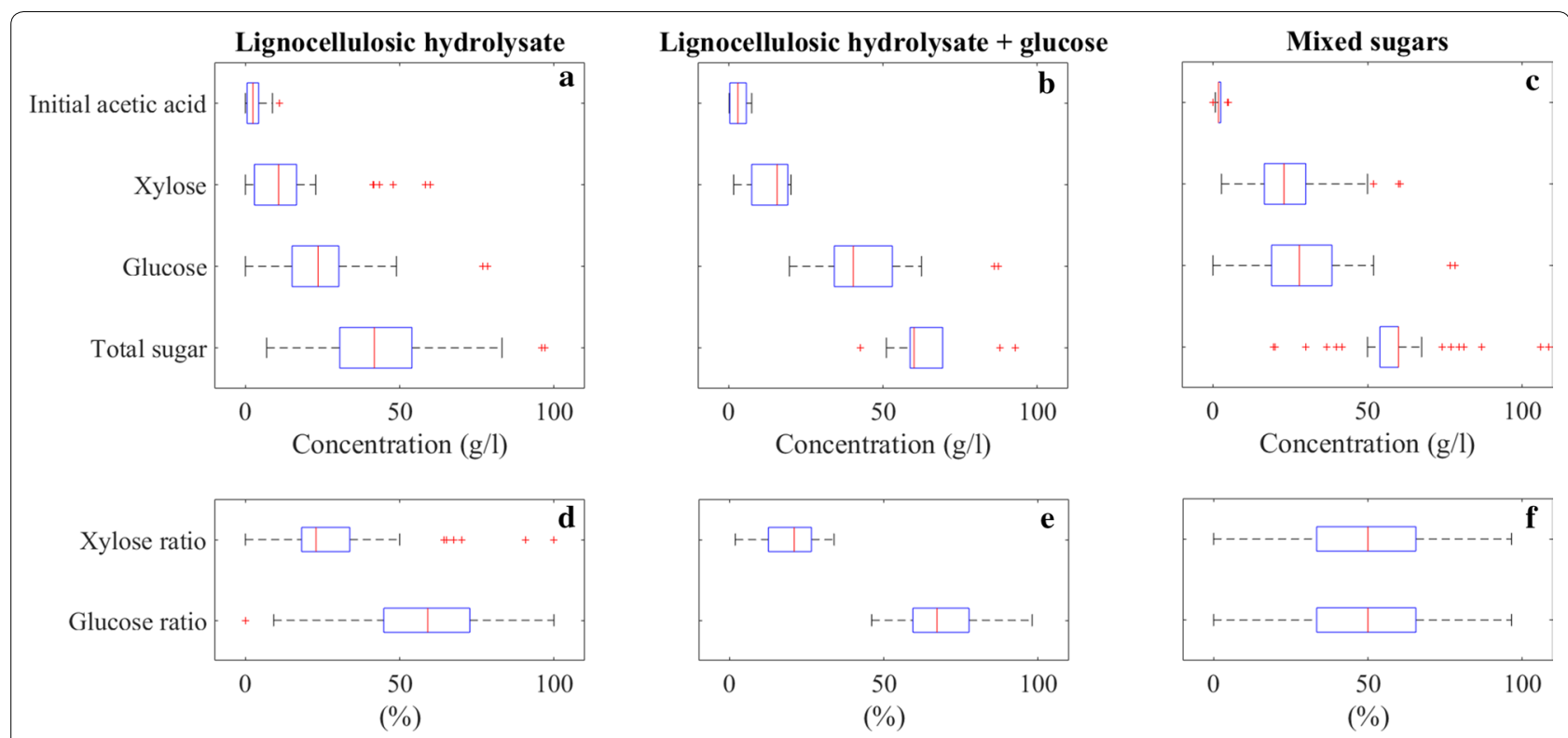

Fig. 4 Substrate properties of lignocellulosic hydrolysate (a, d), lignocellulosic hydrolysate with additional glucose (b, e), and mixed sugar fermentations $(\mathbf{c}, \mathbf{f})$
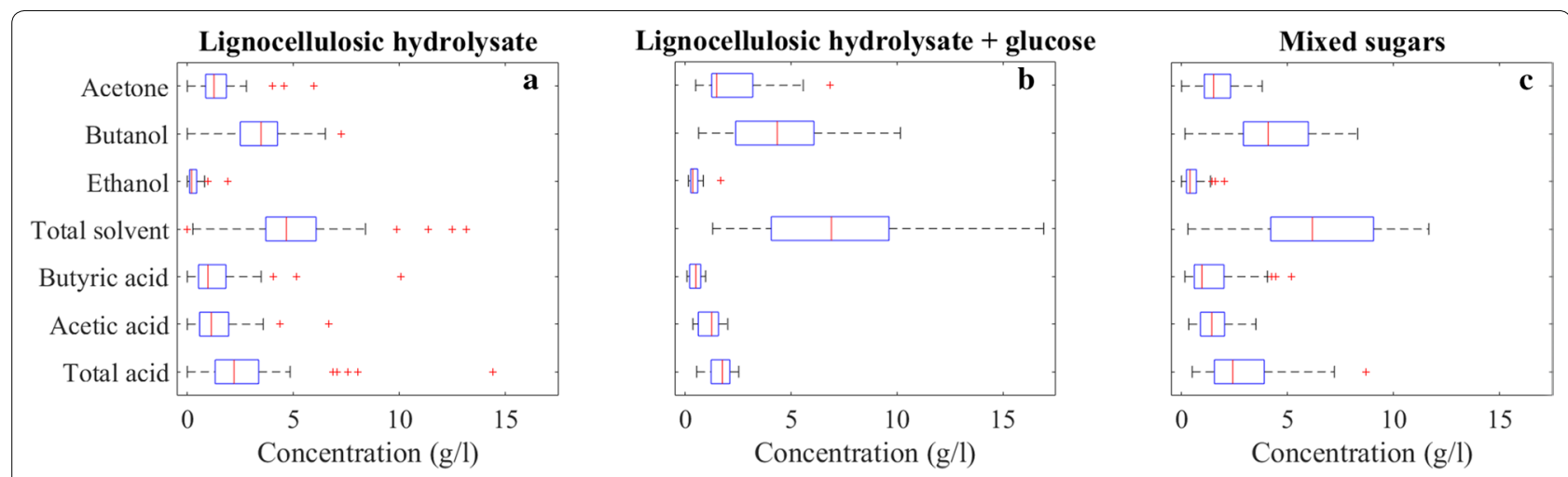

Fig. 5 Product concentrations of lignocellulosic hydrolysate (a), lignocellulosic hydrolysate with additional glucose (b), and mixed sugar fermentations (c)

Xylose ratio decreased from 22.9 to $20.9 \%$, while glucose ratio increased from 59 to $67 \%$.

Mixed sugar fermentations are frequent among published lignocellulosic biomass fermentation studies. Researchers mimic the composition of hydrolysates with synthetic sugars to test the effect of impurities and inhibitors. Mixed sugar concentration values are more disperse with the medians of total sugar, glucose, and xylose concentrations of 60,28 , and $23 \mathrm{~g} / \mathrm{l}$, respectively. Interestingly, glucose and xylose ratios were both $50 \%$. Even though the mixed sugar fermentation studies aim to mimic the original hydrolysate mixtures, their experimental conditions deviate from the actual values. This difference leads to the necessity for a holistic approach as in the objective of this critical review.

\section{Product mixture properties}

Maximization of butanol titer is an all-time objective as discussed above. Moreover, the product mixture can give an idea of the state of the fermentation. Therefore, we took a closer look at the composition and concentrations of the product mixtures, and identified 7 fermentation variables in total for EDA to investigate product mixture properties as shown in Fig. 5.

For lignocellulosic hydrolysate fermentations, the medians of total ABE solvents, acetone, butanol and ethanol 


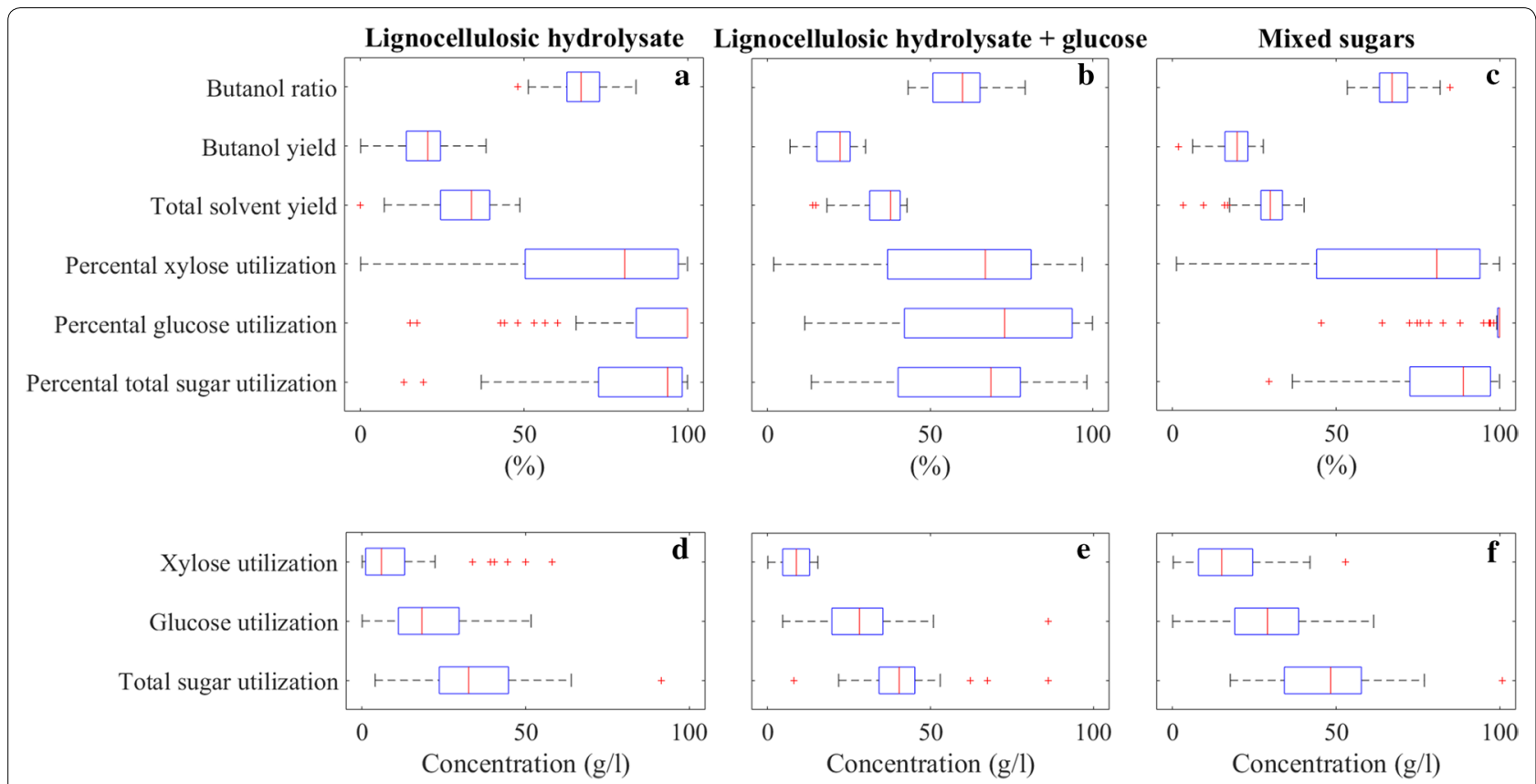

Fig. 6 Performance indicators of lignocellulosic hydrolysate $(\mathbf{a}, \mathbf{d})$, lignocellulosic hydrolysate with additional glucose (b, e), and mixed sugar fermentations $(\mathbf{c}, \mathbf{f})$

concentrations are 9.33, 2.5, 6.95 and $0.4 \mathrm{~g} / \mathrm{l}$, respectively, while the medians of total acid, butyric acid and acetic acid concentrations are 4.4, 1.94 and $2.26 \mathrm{~g} / \mathrm{l}$. The highest reported value of our product of interest, butanol, was $14.5 \mathrm{~g} / \mathrm{l}$ produced by C. beijerinckii P260 [58], shown as an outlier in Fig. 5b. High total acid concentrations of 14.1 and $15.1 \mathrm{~g} / \mathrm{l}$ were reported for switchgrass hydrolysate fermentations by $C$. acetobutylicum 824 , and those were reduced to 5.38 and $4.8 \mathrm{~g} / \mathrm{l}$ after detoxification of the substrate with more than $100 \%$ increase in the total ABE solvent concentrations [51]. Total acid concentrations of 16.1 and $28.8 \mathrm{~g} / \mathrm{l}$ were reported for soybean hull as the feedstock and engineered $C$. tyrobutyricum strains [72]. High acetone concentration in the product mixture is not desirable since it is corrosive to plastic piping and increases downstream costs. Therefore, wheat straw hydrolysate fermentation by C. beijerinckii with $11.9 \mathrm{~g} / \mathrm{l}$ acetone [41] and switchgrass and phragmite hydrolysate fermentations by $C$. saccharobutylicum with 9.13 and $9.15 \mathrm{~g} / \mathrm{l}$ acetone [65], respectively, are worth to mention.

For lignocellulosic hydrolysate with glucose fermentations, the medians of total ABE solvents, acetone, butanol and ethanol concentrations are 13.81, 2.97, 8.69 and $0.71 \mathrm{~g} / \mathrm{l}$, respectively, which are $48 \%, 19 \%, 25 \%$ and $78 \%$ higher than fermentations of lignocellulosic hydrolysates only as reported above. Medians of total acid, butyric acid and acetic acid concentrations are 3.5, 1.0 and $2.5 \mathrm{~g} / \mathrm{l}$, respectively. Additional glucose resulted in an increase in $\mathrm{ABE}$ solvents, and a decrease in total acids, indicating that the fermentations were closer to completion. Fermentation of wheat straw hydrolysate with added glucose by $C$. beijerinckii yielded a high acetone concentration of $13.7 \mathrm{~g} / \mathrm{l}$ [39].

For mixed sugar fermentations, the medians of total $\mathrm{ABE}$ solvents, acetone, butanol and ethanol concentrations are $12.33,3.01,8.17$ and $0.8 \mathrm{~g} / \mathrm{l}$, respectively, while those of total acid, butyric acid and acetic acid concentrations are 4.83, 1.93 and $2.85 \mathrm{~g} / \mathrm{l}$. Even though the initial total substrate concentrations of lignocellulosic hydrolysate with glucose and mixed sugar fermentations were almost the same, the latter had 12\% lower ABE solvents, and 38\% higher total acids. Reasons can be the difference in individual sugar concentrations and the stimulatory effects of compounds present in the hydrolysates [76].

\section{Performance indicators}

We identified percental (\%) utilizations of total sugar, glucose, xylose and arabinose as common individual sugars, butanol and solvent yields in \% (g product/g total sugar consumed $\times 100 \%$ ) and the butanol ratio in $\%$ in $\mathrm{ABE}$ solvents (g butanol/g ABE solvents $\times 100 \%$ ) as the performance indicators for a successful fermentation. Therefore, 9 fermentation variables were considered in total for EDA to investigate performance indicators as shown in Fig. 6. Even though solvent and/or butanol productivity is another important measure, reported values were 
difficult to compare due to the presence of lag phases and low data density, making it difficult to determine the exact time when fermentation had stopped.

For lignocellulosic hydrolysate fermentations, the medians of total sugar, glucose, and xylose utilizations (\%) are 94, 100, and 80.8, respectively, which indicates a rather inefficient use of xylose. Lowest glucose utilizations shown as outliers in Fig. 6 a are $49 \%$ for rice straw hydrolysate fermentation by non-acetone forming $C$. sporogenes [63] and 16\% for switchgrass hydrolysate fermentation by $C$. acetobutylicum 824 that increased to $60 \%$ after detoxification [51]. In a similar manner, $14 \%$ glucose utilization during wheat straw hydrolysate fermentation by $C$. beijerinckii DSM 6422 increased to $76 \%$ after detoxification [52]. Solvent and butanol yields are important measures of cells' efficiency to convert substrate to useful products, and a higher butanol ratio is desirable to minimize downstream processing costs. The medians of total ABE solvent yield, butanol yield and butanol ratio were $34 \%, 25.6 \%$ and $67.5 \%$. The highest butanol yield with $38.4 \%$ was achieved for rice bran hydrolysate fermentation by C. beijerinckii NCIMB 8052 [56], which represents $94 \%$ of the maximum theoretical butanol yield from glucose, $0.41(\mathrm{~g} / \mathrm{g})$ [124]. The highest butanol ratio in ABE solvents was $84.2 \%$ achieved in the same fermentation [56]. It is interesting to note that the butanol ratio was only $64 \%$ in the fermentation by nonacetone forming C. sporogenes [63], which can still be favorable, since the ethanol and butanol blend is already a valuable and useful product mix.

For lignocellulosic hydrolysate fermentations with added glucose, the medians of total sugar, glucose, and xylose utilizations were $68.7 \%, 73 \%$, and $67 \%$, respectively, which are lower than in fermentations of the hydrolysates without added glucose. The reason can be that the substrate concentrations reached inhibitory levels with the added glucose and consequently sugar utilizations became inefficient. Median values of total $\mathrm{ABE}$ solvent yield, butanol yield and butanol ratio were $37.8 \%, 22.3 \%$ and $60 \%$. Despite $11.2 \%$ higher solvent yield, butanol yield and butanol ratio were $13 \%$ and $12.5 \%$ lower compared to lignocellulosic hydrolysate fermentations without extra glucose, which implies that the composition of the sugar mixture has an influence on the product mixture.

For mixed sugar fermentations, the medians of total sugar, glucose, and xylose utilizations are $89 \%, 100 \%$, and $80.8 \%$, respectively. Despite the similar initial total substrate concentrations of lignocellulosic hydrolysate with glucose and mixed sugar fermentations, the latter had $20 \%$ higher total sugar utilization. This can be due to the difference in concentrations of individual sugars and other medium components. Median values of total $\mathrm{ABE}$ solvent yield, butanol yield and butanol ratio were $29.9 \%$, $19.8 \%$ and $67 \%$. Both ABE solvent and butanol yield values were significantly lower than in lignocellulosic hydrolysate with added glucose fermentations. However, the butanol ratio was $11.7 \%$ higher in mixed sugar fermentations.

\section{Correlations between fermentation variables}

We chose Kendall's correlation coefficient to determine the correlations between variables since it is able predict nonlinear relationships [125] and robust in presence of outliers in data [126]. The coefficient has a value between +1 and -1 , where 1 is total positive correlation, 0 is no correlation, and -1 is total negative correlation. All 22 fermentation variables introduced in the previous section was used. They are initial substrate, glucose, xylose and acetic acid concentrations $\left(\mathrm{S}_{\mathrm{i}}, \mathrm{SG}_{\mathrm{i}}, \mathrm{SX}_{\mathrm{i}}\right.$ and $\left.\mathrm{HAc}_{\mathrm{i}}\right)$, ratio of glucose and xylose in the initial substrate mixture $\left(\mathrm{SG}_{\mathrm{ir}}\right.$ and $\left.\mathrm{SX}_{\mathrm{ir}}\right)$, utilized concentrations of total substrate, glucose and xylose $\left(\mathrm{S}_{\mathrm{u}}, \mathrm{SG}_{\mathrm{u}}\right.$ and $\left.\mathrm{SX}_{\mathrm{u}}\right)$, percental utilizations of total substrate, glucose and xylose $\left(\mathrm{S}_{\mathrm{ur}}, \mathrm{SG}_{\mathrm{ur}}\right.$ and $\mathrm{SX}_{\mathrm{ur}}$ ), concentrations of acetone, butanol, ethanol, $\mathrm{ABE}$ solvents, butyric acid, acetic acid and total acids (Ac, $\mathrm{BuOH}, \mathrm{EtOH}, \mathrm{ABE}, \mathrm{HBu}, \mathrm{HAc}$ and acids), $\mathrm{ABE}$ solvents and butanol yields $\left(\mathrm{ABE}_{\mathrm{y}}\right.$ and $\left.\mathrm{BuOH}_{\mathrm{y}}\right)$, and butanol ratio in $\mathrm{ABE}$ solvents $\left(\mathrm{BuOH}_{\mathrm{r}}\right)$. Figure 7 shows values of Kendall's correlation coefficients for each pair of 22 fermentation variables.

All utilized sugar concentrations $\left(\mathrm{S}_{\mathrm{u}}, \mathrm{SG}_{\mathrm{u}}, \mathrm{SX}_{\mathrm{u}}\right)$ increase as their initial concentrations $\left(\mathrm{S}_{\mathrm{i}}, \mathrm{SG}_{\mathrm{i}}, \mathrm{SX}_{\mathrm{i}}\right)$ increase, which reflects into positive and statistically significant correlation coefficients. On the other hand, sugar utilizations $\left(\mathrm{S}_{\mathrm{ur}}, \mathrm{SG}_{\mathrm{ur}}, \mathrm{SX}_{\mathrm{ur}}\right)(\%)$ decrease with increasing initial total sugar $\left(\mathrm{S}_{\mathrm{i}}\right)$ and glucose concentrations $\left(\mathrm{SG}_{\mathrm{i}}\right)$. Even though higher sugar concentration improves fermentation to some extent, beyond some threshold, it starts to become inhibitory and this phenomenon is illustrated with negative correlation coefficients. Furthermore, correlation coefficients show that $\mathrm{SG}_{\mathrm{ur}}$ decreases with increasing initial glucose ratio $\left(\mathrm{SG}_{\mathrm{ir}}\right)$ with correlation coefficient value of -0.25 and increases with increasing initial xylose ratio $\left(\mathrm{SX}_{\mathrm{ir}}\right)$ in the substrate with correlation coefficient value of 0.27 . This seems controversial at first sight. However, high $\mathrm{SG}_{\mathrm{ir}}$ is a result of high $\mathrm{SG}_{\mathrm{i}}$, which leads to lower glucose utilization as explained above. CCR information is another important feature extracted from the correlations. A higher initial glucose ratio $\left(\mathrm{SG}_{\mathrm{ir}}\right)$ and a lower initial xylose ratio $\left(\mathrm{SX}_{\mathrm{ir}}\right)$ leads to an increasing utilized glucose concentration $\left(\mathrm{SG}_{\mathrm{u}}\right)$ with a correlation coefficient of -0.13 for the latter. Similarly, the utilized xylose concentration $\left(\mathrm{SX}_{\mathrm{u}}\right)$ increases with an increasing initial xylose ratio $\left(\mathrm{SX}_{\mathrm{ir}}\right)$, while it decreases as the initial glucose ratio $\left(\mathrm{SG}_{\mathrm{ir}}\right)$ increases with 


\begin{tabular}{|c|c|c|c|c|c|c|c|c|c|c|c|c|c|c|c|c|c|c|c|c|c|c|}
\hline $\mathrm{S}_{\mathrm{i}}$ & 1.00 & 0.49 & 0.41 & 0.05 & \begin{tabular}{|l|l|} 
\\
\end{tabular} & 0.13 & 0.54 & -0.24 & 0.39 & -0.15 & 0.20 & -0.13 & 0.29 & 0.27 & 0.30 & 0.31 & \begin{tabular}{|l|l|}
0.17 \\
\end{tabular} & 0.26 & 0.16 & -0.09 & \begin{tabular}{|l|}
-0.19 \\
\end{tabular} & -0.16 \\
\hline SG. & 0.49 & 1.00 & -0.02 & 0.56 & -0.27 & 0.36 & 0.31 & -0.20 & 0.75 & -0.24 & -0.11 & -0.16 & 0.30 & 0.25 & 0.23 & 0.29 & 0.07 & 0.16 & 0.09 & 0.03 & \begin{tabular}{|l|l}
-0.08 \\
\end{tabular} & -0.14 \\
\hline$s x_{i}^{\prime}$ & 0.41 & \begin{tabular}{|l|}
-0.02 \\
\end{tabular} & 1.00 & -0.40 & 0.73 & -0.05 & 0.33 & -0.06 & 0.05 & 0.18 & 0.61 & 0.00 & 0.11 & 0.11 & 0.33 & 0.15 & \begin{tabular}{|l|l|}
0.07 \\
\end{tabular} & 0.12 & 0.06 & -0.14 & -0.20 & -0.08 \\
\hline $\begin{array}{l}\mathrm{SG}_{\mathrm{i}} \\
\mathrm{S}\end{array}$ & 0.05 & 0.56 & -0.40 & 1.00 & -0.52 & 0.42 & -0.00 & -0.03 & 0.43 & -0.25 & -0.33 & -0.04 & 0.14 & 0.07 & 0.01 & 0.09 & -0.08 & -0.05 & -0.09 & 0.07 & 0.05 & -0.11 \\
\hline ir & 0.13 & -0.27 & 0.73 & -0.52 & 1.00 & -0.14 & 0.14 & 0.06 & -0.13 & \begin{tabular}{|l|}
0.27 \\
\end{tabular} & 0.56 & 0.12 & -0.01 & -0.00 & 0.21 & 0.02 & -0.02 & -0.01 & -0.03 & -0.16 & -0.16 & -0.04 \\
\hline $\mathrm{S}_{\mathrm{ir}}$ & 0.13 & 0.36 & -0.05 & 0.42 & -0.14 & 1.00 & 0.08 & -0.07 & 0.25 & -0.27 & 0.04 & 0.17 & 0.24 & 0.30 & -0.00 & 0.27 & -0.06 & 0.25 & 0.17 & 0.36 & \begin{tabular}{|l|}
0.33 \\
\end{tabular} & 0.11 \\
\hline $\mathrm{HAc}_{\mathrm{i}}$ & 0.54 & 0.31 & 0.33 & -0.00 & 0.14 & 0.08 & 1.00 & \begin{tabular}{|l|}
0.23 \\
\end{tabular} & 0.47 & 0.21 & 0.44 & 0.21 & 0.53 & 0.56 & 0.38 & 0.64 & 0.05 & 0.17 & 0.10 & 0.07 & -0.04 & -0.07 \\
\hline $\mathrm{S}_{\mathrm{u}}$ & -0.24 & -0.20 & -0.06 & -0.03 & 0.06 & -0.07 & 0.23 & 1.00 & 0.01 & 0.55 & 0.24 & 0.61 & 0.22 & 0.27 & 0.12 & 0.25 & -0.08 & -0.08 & -0.08 & 0.23 & 0.20 & 0.05 \\
\hline $\mathrm{S}_{\mathrm{ur}}$ & 0.39 & 0.75 & 0.05 & 0.43 & -0.13 & 0.25 & 0.47 & 0.01 & 1.00 & \begin{tabular}{|l|}
0.09 \\
\end{tabular} & -0.01 & -0.08 & 0.38 & 0.33 & 0.22 & \begin{tabular}{|l|}
0.38 \\
\end{tabular} & \begin{tabular}{|l|}
0.08 \\
\end{tabular} & \begin{tabular}{|l|}
0.19 \\
\end{tabular} & 0.13 & 0.04 & -0.05 & -0.02 \\
\hline $\mathrm{SG}_{\mathrm{u}}$ & -0.15 & -0.24 & 0.18 & -0.25 & 0.27 & \begin{tabular}{|l|l|} 
\\
\end{tabular} & 0.21 & 0.55 & 0.09 & 1.00 & 0.20 & 0.21 & 0.10 & 0.18 & 0.18 & 0.17 & \begin{tabular}{|l|l|}
0.12 \\
\end{tabular} & 0.07 & 0.10 & 0.09 & 0.10 & 0.18 \\
\hline $\mathrm{SG}_{\mathrm{ur}}$ & 0.20 & \begin{tabular}{|l|l|}
-0.11 \\
\end{tabular} & 0.61 & -0.33 & 0.56 & 0.04 & 0.44 & 0.24 & -0.01 & 0.20 & 1.00 & 0.41 & 0.26 & 0.31 & 0.33 & 0.32 & -0.14 & -0.02 & -0.09 & 0.01 & \begin{tabular}{|c|}
-0.01 \\
\end{tabular} & -0.06 \\
\hline $\mathrm{SX}_{\mathrm{u}}$ & -0.13 & -0.16 & 0.00 & -0.04 & 0.12 & \begin{tabular}{|l|l|} 
\\
\end{tabular} & 0.21 & 0.61 & -0.08 & \begin{tabular}{|l|l|} 
\\
\end{tabular} & 0.41 & 1.00 & 0.24 & 0.22 & 0.12 & 0.22 & \begin{tabular}{|l|l|} 
\\
\end{tabular} & -0.13 & -0.20 & 0.14 & 0.16 & -0.01 \\
\hline $\mathrm{Sx}_{\mathrm{u}}$ & 0.29 & 0.30 & 0.11 & 0.14 & -0.01 & 0.24 & 0.53 & 0.22 & 0.38 & 0.10 & 0.26 & 0.24 & 1.00 & 0.62 & 0.23 & 0.73 & -0.22 & -0.00 & -0.13 & 0.41 & \begin{tabular}{|l|}
0.27 \\
\end{tabular} & -0.26 \\
\hline $\mathrm{Ac}$ & 0.27 & 0.25 & 0.11 & 0.07 & -0.00 & 0.30 & 0.56 & 0.27 & 0.33 & 0.18 & 0.31 & 0.22 & 0.62 & 1.00 & 0.29 & 0.86 & -0.15 & \begin{tabular}{|l}
0.07 \\
\end{tabular} & -0.05 & 0.42 & \begin{tabular}{|l|l|}
0.40 \\
\end{tabular} & 0.08 \\
\hline $\mathrm{BuOH}$ & 0.30 & 0.23 & 0.33 & 0.01 & 0.21 & -0.00 & 0.38 & 0.12 & 0.22 & \begin{tabular}{|l}
0.18 \\
\end{tabular} & 0.33 & 0.12 & 0.23 & 0.29 & 1.00 & 0.34 & -0.05 & \begin{tabular}{|l|l|} 
\\
\end{tabular} & -0.01 & 0.03 & -0.02 & -0.22 \\
\hline EtOH & 0.31 & 0.29 & 0.15 & 0.09 & 0.02 & 0.27 & 0.64 & \begin{tabular}{|l|}
0.25 \\
\end{tabular} & 0.38 & 0.17 & 0.32 & 0.22 & 0.73 & 0.86 & 0.34 & 1.00 & \begin{tabular}{|l|}
-0.19 \\
\end{tabular} & 0.07 & -0.07 & 0.43 & \begin{tabular}{|l|}
0.36 \\
\end{tabular} & -0.06 \\
\hline $\mathrm{ABE}$ & 0.17 & \begin{tabular}{|l|l|}
0.07 \\
\end{tabular} & 0.07 & -0.08 & -0.02 & -0.06 & 0.05 & -0.08 & 0.08 & \begin{tabular}{|l|l|}
0.12 \\
\end{tabular} & -0.14 & -0.24 & -0.22 & -0.15 & -0.05 & -0.19 & 1.00 & 0.42 & 0.66 & -0.23 & -0.29 & 0.08 \\
\hline $\begin{array}{l}\mathrm{HBU} \\
\mathrm{HAC}\end{array}$ & 0.26 & 0.16 & 0.12 & -0.05 & -0.01 & 0.25 & 0.17 & -0.08 & 0.19 & \begin{tabular}{|l|}
0.07 \\
\end{tabular} & -0.02 & -0.13 & -0.00 & 0.07 & 0.07 & 0.07 & 0.42 & 1.00 & 0.76 & 0.09 & -0.05 & \begin{tabular}{|l|l|}
0.14 \\
\end{tabular} \\
\hline Acids & 0.16 & \begin{tabular}{|l|l|} 
\\
\end{tabular} & 0.06 & \begin{tabular}{|l|l|}
-0.09 \\
\end{tabular} & -0.03 & \begin{tabular}{|l|l|}
0.17 \\
\end{tabular} & 0.10 & -0.08 & 0.13 & \begin{tabular}{|l|}
0.10 \\
\end{tabular} & -0.09 & -0.20 & -0.13 & -0.05 & -0.01 & -0.07 & \begin{tabular}{|l|}
0.66 \\
\end{tabular} & 0.76 & 1.00 & -0.08 & \begin{tabular}{|c|c|} 
\\
\end{tabular} & \begin{tabular}{|l|}
0.15 \\
\end{tabular} \\
\hline $\mathrm{ABE}_{\mathrm{y}}$ & -0.09 & 0.03 & -0.14 & 0.07 & -0.16 & 0.36 & 0.07 & 0.23 & 0.04 & \begin{tabular}{|l|}
0.09 \\
\end{tabular} & 0.01 & 0.14 & 0.41 & \begin{tabular}{|l|l|}
0.42 \\
\end{tabular} & \begin{tabular}{|l|}
0.03 \\
\end{tabular} & 0.43 & -0.23 & 0.09 & \begin{tabular}{|c|}
-0.08 \\
\end{tabular} & 1.00 & \begin{tabular}{|l|l}
0.74 \\
\end{tabular} & 0.05 \\
\hline $\mathrm{BuOH}_{\mathrm{y}}$ & -0.19 & -0.08 & -0.20 & 0.05 & -0.16 & 0.33 & -0.04 & 0.20 & -0.05 & \begin{tabular}{|l|l|}
0.10 \\
\end{tabular} & -0.01 & 0.16 & 0.27 & 0.40 & -0.02 & 0.36 & -0.29 & -0.05 & \begin{tabular}{|l|l|} 
& -0.17 \\
\end{tabular} & 0.74 & 1.00 & 0.31 \\
\hline $\mathrm{BuOH}^{3}$ & -0.16 & -0.14 & -0.08 & -0.11 & -0.04 & 0.11 & -0.07 & 0.05 & -0.02 & 0.18 & -0.06 & -0.01 & -0.26 & 0.08 & -0.22 & -0.06 & 0.08 & 0.14 & \begin{tabular}{|l|l|}
0.15 \\
\end{tabular} & 0.05 & \begin{tabular}{|l|}
0.31 \\
\end{tabular} & 1.00 \\
\hline
\end{tabular}

a correlation coefficient of -0.33 . Therefore, both sugars repress each other's utilization due to CCR. However, the repression effect is greater from glucose to xylose $(|-0.33|>|-0.13|)$ as suggested in our previous work cite [127].

As the correlation coefficients in Fig. 7 indicate, all product concentrations increase with increasing initial concentrations of all sugars; acetone (Ac) and butanol $(\mathrm{BuOH})$ concentrations are more influenced by initial glucose $\left(\mathrm{SG}_{\mathrm{i}}\right)$ than xylose $\left(\mathrm{SX}_{\mathrm{i}}\right)$, and $\mathrm{SGi}$ has a greater influence on Ac (0.30) than on $\mathrm{BuOH}(0.25)$. This is in line with previous work where no acetone accumulation was found during fermentation of xylose by $C$. acetobutylicum [109]. Both solvent yield $\left(\mathrm{ABE}_{\mathrm{y}}\right)$ and butanol yield $\left(\mathrm{BuOH}_{\mathrm{y}}\right)$ decrease with increasing initial xylose concentration $\left(\mathrm{SX}_{\mathrm{i}}\right)$ and ratio $\left(\mathrm{SX}_{\mathrm{ir}}\right)$, while they increase with elevated initial acetic acid concentration $\left(\mathrm{HAc}_{\mathrm{i}}\right)$ that is often generated during pretreatment of lignocellulosic biomass. Negative correlation coefficient between xylose and yields could be due to the carbon content of one xylose molecule containing one carbon less than glucose, thus one xylose molecule has less capacity to yield products. Positive correlation between $\mathrm{ABE}_{\mathrm{y}}$ and $\mathrm{BuOH}_{\mathrm{y}}$, and $\mathrm{HAc}_{\mathrm{i}}$ can be due to presence of acetic acid in the beginning of fermentation facilitating solvent formation, which is line with metabolic pathway of fermentation [6]. Another crucial performance indicator, the butanol ratio $\left(\mathrm{BuOH}_{\mathrm{r}}\right)$, becomes greater as $\mathrm{S}_{\mathrm{i}}, \mathrm{SG}_{\mathrm{i}}$, and $\mathrm{SG}_{\mathrm{ir}}$ decrease. Furthermore, all product concentrations except $\mathrm{HBu}$ and $\mathrm{EtOH}$ increase with increasing $\mathrm{HAc}_{\mathrm{i}}$. Some researchers stated that high initial acetic acid concentrations could facilitate acetone formation, consequently increase the acetone to butanol ratio [101]. However, the correlation coefficient between $\mathrm{HAc}_{\mathrm{i}}$ and $\mathrm{BuOH}$ is greater than that of $\mathrm{HAc}_{\mathrm{i}}$ and Ac, i.e. 0.30 and 0.24 , respectively. Therefore, a potential effect of initial acetic acid concentrations in the fermentation medium on product formation needs to be studied in more detail.

Correlation coefficients between utilized sugar concentrations $\left(\mathrm{S}_{\mathrm{u}}, \mathrm{SX}_{\mathrm{u}}\right)$ and sugar utilizations $\left(\mathrm{S}_{\mathrm{ur}}, \mathrm{SX}_{\mathrm{ur}}\right)$ are positive, indicating the more the utilized sugar concentration, the higher the utilization (\%) with respect to its initial concentration. In addition, all solvent concentrations ( $\mathrm{ABE}, \mathrm{Ac}, \mathrm{BuOH}, \mathrm{EtOH})$ increase with increasing $\mathrm{S}_{\mathrm{u}}, \mathrm{SG}_{\mathrm{u}}, \mathrm{SX}_{\mathrm{u}}, \mathrm{S}_{\mathrm{ur}}, \mathrm{SG}_{\mathrm{ur}}$, and $\mathrm{SX}_{\mathrm{ur}}$. One exception to this trend is that there is no significant correlation between $\mathrm{SG}_{\mathrm{ur}}$ and Ac. HAc is in positive correlation with $\mathrm{S}_{\mathrm{u}}$ and $\mathrm{SG}_{\mathrm{u}}$, while $\mathrm{HBu}$ is in negative correlation with $\mathrm{SX}_{\mathrm{u}}$ and $\mathrm{SX}_{\mathrm{ur}}$. Even though both acids are produced as the cells metabolize glucose and xylose, the difference in the effects of specific sugars in the metabolic pathway is apparent.

$\mathrm{Ac}$ and $\mathrm{BuOH}$ concentrations decrease with increasing $\mathrm{HBu}$ concentration, while there is no correlation with HAc. Therefore, the $\mathrm{HBu}$ concentration alone can be considered as a measure of fermentation completion. $\mathrm{EtOH}$ is not correlated with any of the acid products, which is in good agreement with the kinetic model developed by Shinto et al. [128]. 


\section{Conclusions}

To develop new strategies to increase the overall competitiveness of fermentative butanol production from lignocellulosic biomass by clostridia, it is crucial to have an overall view of all relevant process aspects and characteristics. One of the main challenges is expensive fermentation substrate, accounting for $66 \%$ of the total costs [33]. Besides availability, supply and storage issues, efficient conversion of the feedstock to fermentable sugars remain costly. Therefore, it is significant to develop new, more cost-efficient pretreatment methods that minimize the generation of inhibitors, energy consumption, operating cost, and simultaneously maximize fermentable sugar yield with a careful consideration of feedstock properties. In addition, adapting and developing strains, which can effectively utilize all the sugars present in the substrate [56] and better tolerate inhibitors can contribute to the solution. Downstream processing has the second highest share in the overall cost (16\%) [33]. Higher product concentrations and ratios can make this process more economically feasible. However, the solvent toxicity problem and the generation of undesirable by-products, i.e. acetone and ethanol, are necessary to overcome. Even though metabolic engineering has provided different alternatives such as improved solvent tolerance and nonacetone forming strains, those still need to be tested over a prolonged time under different operating conditions and further improved e.g. by means of systems biology guided strain engineering and Synthetic biology to gain and sustain industrial viability.

Understanding the process variables and performance indicators has been lacking to a great extent, since many studies narrow their focus to a particular problem and evaluate their solution in the same narrow window. To illustrate the benefits of having a holistic view, we have developed a dataset by collecting fermentation data and performed an EDA. The results show that common practices such as addition of glucose to achieve a high sugar concentration could have detrimental effects on production performance, and unexpected trends might occur depending on process design choices. The EDA results provided insight into typical operating conditions as well as performance indicators. The correlation results showed that common practices such as addition of glucose to achieve a high sugar concentration could have detrimental effects on production performance. Moreover, correlation between different fermentation variables revealed several important trends, which confirms previous observations or contradicts some current argumentations. Correlation between the initial ratios of glucose and xylose and their utilizations during mixed sugar fermentations unveiled that CCR was active for both sugars, confirming previous observations [127]. On the other hand, our correlation findings contradict with the common belief that the acetic acid generated in biomass pretreatment can result in increased acetone formation. Therefore, it is very important to note that correlation does not necessarily imply causation and a careful attendance is necessary when utilizing correlation information in design of processes both in lab scale and in industrial scale. Furthermore, usefulness of EDA results heavily depends on the quality of the reported data. Further efforts in the field need to focus on reporting detailed information about pretreatment conditions and studying their influence on fermentation performance. All in all, this approach provides different insights and information as a guide to a more successful fermentation of lignocellulosic sugars to butanol as a key to more competitive butanol production processes for biofuel applications in the future.

\section{Additional file}

Additional file 1. Fermentation dataset.

\section{Acknowledgements \\ Not applicable.}

\section{Authors' contributions}

CB defined the aim and scope of this review article, collected the literature data, and performed exploratory analysis with the developed dataset. CB wrote the major parts of the manuscript. PD and AW contributed to writing and all authors contributed revising and editing it. All authors read and approved the final manuscript.

Funding

This work was supported by the Research Council of Norway, Grant No. 246821/E20 (EcoLodge) and Grant No. 284538/O70 of the ERA-net Cofund on Biotechnologies (ERA CoBioTech) project BESTER.

Availability of data and materials

All data generated or analyzed during this study are included in this published article and its additional file.

Ethics approval and consent to participate

Not applicable.

Consent for publication

Not applicable.

Competing interests

The authors declare that they have no competing interests.

Author details

${ }^{1}$ Department of Chemical Engineering, NTNU, 7491 Trondheim, Norway.

${ }^{2}$ Institute of Microbiology and Biotechnology, Ulm University, 89069 Ulm, Germany. ${ }^{3}$ SINTEF Industry, 7465 Trondheim, Norway.

Received: 4 April 2019 Accepted: 19 June 2019

Published online: 28 June 2019 


\section{References}

1. Ranjan A, Moholkar VS. Biobutanol: science, engineering, and economics. Int J Energy Res. 2012;36(3):277-323.

2. Campos-Fernández J, Arnal JM, Gómez J, Dorado MP. A comparison of performance of higher alcohols/diesel fuel blends in a diesel engine. Appl Energy. 2012;95:267-75.

3. Bharathiraja B, Jayamuthunagai J, Sudharsanaa T, Bharghavi A, Praveenkumar R, Chakravarthy M, et al. Biobutanol_an impending biofuel for future: a review on upstream and downstream processing tecniques. Renew Sustain Energy Rev. 2017;68:788-807.

4. da Silva Trindade WR, dos Santos RG. Review on the characteristics of butanol, its production and use as fuel in internal combustion engines. Renew Sustain Energy Rev. 2017;69:642-51.

5. Pasteur $L$. Quelques résultats nouveaux relatifs aux fermentations acétique et butyrique. Bull Soc Chim Paris. 1862:52-3.

6. Jones DT, Woods DR. Acetone-butanol fermentation revisited. Microbiol Rev. 1986;50(4):484.

7. Moon HG, Jang Y-S, Cho C, Lee J, Binkley R, Lee SY. One hundred years of clostridial butanol fermentation. FEMS Microbiol Lett. 2016;363(3):fnw001.

8. Rose AH. Industrial microbiology. Stroudsburg: Dowden, Hutchinson \& Ross; 1961.

9. Dürre P. New insights and novel developments in clostridial acetone/ butanol/isopropanol fermentation. Appl Microbiol Biotechnol. 1998;49(6):639-48.

10. Rogers P, Chen J-S, Zidwick MJ. Organic acid and solvent production. The prokaryotes. Springer: New York; 2006. p. 511-755.

11. Zverlov V, Berezina O, Velikodvorskaya G, Schwarz W. Bacterial acetone and butanol production by industrial fermentation in the Soviet Union: use of hydrolyzed agricultural waste for biorefinery. Appl Microbiol Biotechnol. 2006:71(5):587-97.

12. Jang Y-S, Malaviya A, Cho C, Lee J, Lee SY. Butanol production from renewable biomass by clostridia. Bioresour Technol. 2012;123:653-63.

13. Jurgens $G$, Survase $S$, Berezina O, Sklavounos E, Linnekoski J, Kurkijärvi A, et al. Butanol production from lignocellulosics. Biotechnol Lett 2012:34(8):1415-34

14. Gottumukkala LD, Haigh K, Görgens J. Trends and advances in conversion of lignocellulosic biomass to biobutanol: microbes, bioprocesses and industrial viability. Renew Sustain Energy Rev. 2017;76:963-73.

15. Qureshi N, Ezeji TC. Butanol,'a superior biofuel' production from agricultural residues (renewable biomass): recent progress in technology. Biofuels Bioprod Biorefin. 2008:2(4):319-30.

16. Wang $\mathrm{Y}, \mathrm{Ho}$ S-H, Yen H-W, Nagarajan D, Ren N-Q, Li S, et al. Current advances on fermentative biobutanol production using third generation feedstock. Biotechnol Adv. 2017;35(8):1049-59.

17. Dürre P. Butanol formation from gaseous substrates. FEMS Microbiol Lett. 2016;363(6):fnw040.

18. Maiti S, Gallastegui G, Sarma SJ, Brar SK, Le Bihan Y, Drogui P, et al. A re-look at the biochemical strategies to enhance butanol production. Biomass Bioenergy. 2016;94:187-200.

19. Xue C, Zhao J, Liu F, Lu C, Yang S-T, Bai F-W. Two-stage in situ gas stripping for enhanced butanol fermentation and energy-saving product recovery. Bioresour Technol. 2013;135:396-402.

20. Knoshaug EP, Zhang M. Butanol tolerance in a selection of microorganisms. Appl Biochem Biotechnol. 2009;153(1-3):13-20.

21. Patakova P, Kolek J, Sedlar K, Koscova P, Branska B, Kupkova K, et al. Comparative analysis of high butanol tolerance and production in clostridia. Biotechnol Adv. 2017:36(3):721-38.

22. Kujawska A, Kujawski J, Bryjak M, Kujawski W. ABE fermentation products recovery methods - a review. Renew Sustain Energy Rev. 2015;48:648-61

23. Lee S-H, Yun EJ, Kim J, Lee SJ, Um Y, Kim KH. Biomass, strain engineering, and fermentation processes for butanol production by solventogenic clostridia. Appl Microbiol Biotechnol. 2016;100(19):8255-71.

24. Jang YS, Lee J, Malaviya A, Cho JH, Lee SY. Butanol production from renewable biomass: rediscovery of metabolic pathways and metabolic engineering. Biotechnol J. 2012;7(2):186-98.

25. Huang H, Liu H, Gan Y-R. Genetic modification of critical enzymes and involved genes in butanol biosynthesis from biomass. Biotechnol Adv. 2010;28(5):651-7.
26. Gheshlaghi R, Scharer J, Moo-Young M, Chou C. Metabolic pathways of clostridia for producing butanol. Biotechnol Adv. 2009;27(6):764-81.

27. Nanda S, Golemi-Kotra D, McDermott JC, Dalai AK, Gökalp I, Kozinski JA Fermentative production of butanol: perspectives on synthetic biology. New Biotechnol. 2017:37:210-21.

28. Xue C, Zhao J, Chen L, Yang S-T, Bai F. Recent advances and state-of-theart strategies in strain and process engineering for biobutanol production by Clostridium acetobutylicum. Biotechnol Adv. 2017;35(2):310-22.

29. GuY, Jiang Y, Yang S, Jiang W. Utilization of economical substratederived carbohydrates by solventogenic clostridia: pathway dissection, regulation and engineering. Curr Opin Biotechnol. 2014;29:124-31.

30. Yang Y, Nie X, Jiang Y, Yang C, Gu Y, Jiang W. Metabolic regulation in solventogenic clostridia: regulators, mechanisms and engineering. Biotechnol Adv. 2018;36(4):905-14.

31. Patakova P, Linhova M, Rychtera M, Paulova L, Melzoch K. Novel and neglected issues of acetone-butanol-ethanol (ABE) fermentation by clostridia: clostridium metabolic diversity, tools for process mapping and continuous fermentation systems. Biotechnol Adv. 2013;31(1):58-67.

32. Visioli LJ, Enzweiler H, Kuhn RC, Schwaab M, Mazutti MA. Recent advances on biobutanol production. Sustain Chem Processes. 2014;2(1):15.

33. Jiang Y, Liu J, Jiang W, Yang Y, Yang S. Current status and prospects of industrial bio-production of $n$-butanol in China. Biotechnol Adv. 2015:33(7):1493-501.

34. Jin C, Yao M, Liu H, Chia-fon FL, Ji J. Progress in the production and application of $n$-butanol as a biofuel. Renew Sustain Energy Rev. 2011;15(8):4080-106.

35. Dürre P. Fermentative production of butanol — the academic perspective. Curr Opin Biotechnol. 2011;22(3):331-6.

36. Hillmann F, Fischer RJ, Saint-Prix F, Girbal L, Bahl H. PerR acts as a switch for oxygen tolerance in the strict anaerobe Clostridium acetobutylicum. Mol Microbiol. 2008;68(4):848-60.

37. Zaldivar J, Nielsen J, Olsson L. Fuel ethanol production from lignocellulose: a challenge for metabolic engineering and process integration. Appl Microbiol Biotechnol. 2001;56(1-2):17-34.

38. Carvalheiro F, Duarte LC, Gírio FM. Hemicellulose biorefineries: a review on biomass pretreatments. J Sci Ind Res. 2008;67:849-64.

39. Kalogiannis K, Stefanidis S, Marianou A, Michailof C, Kalogianni A, Lappas A. Lignocellulosic biomass fractionation as a pretreatment step for production of fuels and green chemicals. Waste Biomass Valorization. 2015:6(5):781-90.

40. Sannigrahi P, Ragauskas AJ. Fundamentals of biomass pretreatment by fractionation. Aqueous pretreatment of plant biomass for biological and chemical conversion to fuels and chemicals. Wiley: Chichester; 2013. p. 201-22.

41. Qureshi N, Saha BC, Cotta MA. Butanol production from wheat straw hydrolysate using Clostridium beijerinckii. Bioprocess Biosyst Eng. 2007:30(6):419-27.

42. Su H, Liu G, He M, Tan F. A biorefining process: sequential, combinational lignocellulose pretreatment procedure for improving biobutanol production from sugarcane bagasse. Bioresour Technol. 2015:187:149-60.

43. Zhang Y, Hou T, Li B, Liu C, Mu X, Wang H. Acetone-butanol-ethanol production from corn stover pretreated by alkaline twin-screw extrusion pretreatment. Bioprocess Biosyst Eng. 2014;37(5):913-21.

44. Kong X, Xu H, Wu H, Wang C, He A, Ma J, et al. Biobutanol production from sugarcane bagasse hydrolysate generated with the assistance of gamma-valerolactone. Process Biochem. 2016;51(10):1538-43.

45. Baldry C, Bucke C, Coombs J. Progressive release of carboxylating enzymes during mechanical grinding of sugar cane leaves. Planta. 1971:97(4):310-9.

46. Mikkola J-P, Kirilin A, Tuuf J-C, Pranovich A, Holmbom B, Kustov LM, et al. Ultrasound enhancement of cellulose processing in ionic liquids: from dissolution towards functionalization. Green Chem. 2007;9(11):1229-37.

47. Lan W, Liu C-F, Yue F-X, Sun R-C, Kennedy JF. Ultrasound-assisted dissolution of cellulose in ionic liquid. Carbohydr Polym. 2011;86(2):672-7.

48. Ezeji T, Blaschek HP. Fermentation of dried distillers' grains and solubles (DDGS) hydrolysates to solvents and value-added products by solventogenic clostridia. Bioresour Technol. 2008:99(12):5232-42. 
49. Sun Z, Liu S. Production of $n$-butanol from concentrated sugar maple hemicellulosic hydrolysate by Clostridia acetobutylicum ATCC824. Biomass Bioenergy. 2012;39:39-47.

50. Wang L, Chen H. Increased fermentability of enzymatically hydrolyzed steam-exploded corn stover for butanol production by removal of fermentation inhibitors. Process Biochem. 2011;46(2):604-7.

51. Liu K, Atiyeh HK, Pardo-Planas O, Ezeji TC, Ujor V, Overton JC, et al. Butanol production from hydrothermolysis-pretreated switchgrass: quantification of inhibitors and detoxification of hydrolyzate. Bioresour Technol. 2015;189:292-301.

52. Bellido C, Pinto ML, Coca M, González-Benito G, García-Cubero MT. Acetone-butanol-ethanol (ABE) production by Clostridium beijerinckii from wheat straw hydrolysates: efficient use of penta and hexa carbohydrates. Bioresour Technol. 2014;167:198-205.

53. Qureshi N, Saha BC, Hector RE, Hughes SR, Cotta MA. Butanol production from wheat straw by simultaneous saccharification and fermentation using Clostridium beijerinckii: part I-batch fermentation. Biomass Bioenergy. 2008;32(2):168-75.

54. Qureshi N, Ezeji TC, Ebener J, Dien BS, Cotta MA, Blaschek HP. Butanol production by Clostridium beijerinckii. Part I: use of acid and enzyme hydrolyzed corn fiber. Bioresour Technol. 2008;99(13):5915-22.

55. Hipolito CN, Crabbe E, Badillo CM, Zarrabal OC, Mora MAM, Flores GP, et al. Bioconversion of industrial wastewater from palm oil processing to butanol by Clostridium saccharoperbutylacetonicum N1-4 (ATCC 13564). J Clean Prod. 2008;16(5):632-8.

56. Lee J-E, Seo E-J, Kweon D-H, Park K-M, Jin Y-S. Fermentation of rice bran and defatted rice bran for butanol production using Clostridium beijerinckii NCIMB 8052. J Microbiol Biotechnol. 2009;19(5):482-90

57. Qureshi N, Saha BC, Dien B, Hector RE, Cotta MA. Production of butanol (a biofuel) from agricultural residues: part I—use of barley straw hydrolysate. Biomass Bioenergy. 2010;34(4):559-65.

58. Qureshi N, Saha BC, Hector RE, Dien B, Hughes S, Liu S, et al. Production of butanol (a biofuel) from agricultural residues: part II-use of corn stover and switchgrass hydrolysates. Biomass Bioenergy. 2010:34(4):566-71.

59. Liu Z, Ying Y, Li F, Ma C, Xu P. Butanol production by Clostridium beijerinckii ATCC 55025 from wheat bran. J Ind Microbiol Biotechnol. 2010;37(5):495-501.

60. Lu C, Zhao J, Yang S-T, Wei D. Fed-batch fermentation for $n$-butanol production from cassava bagasse hydrolysate in a fibrous bed bioreactor with continuous gas stripping. Bioresour Technol. 2012;104:380-7.

61. Wang Y, Blaschek HP. Optimization of butanol production from tropical maize stalk juice by fermentation with Clostridium beijerinckii NCIMB 8052. Bioresour Technol. 2011;102(21):9985-90.

62. Moradi F, Amiri H, Soleimanian-Zad S, Ehsani MR, Karimi K. Improvement of acetone, butanol and ethanol production from rice straw by acid and alkaline pretreatments. Fuel. 2013;112:8-13.

63. Gottumukkala LD, Parameswaran B, Valappil SK, Mathiyazhakan K, Pandey A, Sukumaran RK. Biobutanol production from rice straw by a non acetone producing Clostridium sporogenes BE01. Bioresour Technol. 2013;145:182-7.

64. Amiri H, Karimi K, Zilouei H. Organosolv pretreatment of rice straw for efficient acetone, butanol, and ethanol production. Bioresour Technol. 2014;152:450-6.

65. Gao K, Boiano S, Marzocchella A, Rehmann L. Cellulosic butanol production from alkali-pretreated switchgrass (Panicum virgatum) and phragmites (Phragmites australis). Bioresour Technol. 2014;174:176-81.

66. Qureshi N, Saha BC, Hector RE, Cotta MA. Removal of fermentation inhibitors from alkaline peroxide pretreated and enzymatically hydrolyzed wheat straw: production of butanol from hydrolysate using Clostridium beijerinckii in batch reactors. Biomass Bioenergy. 2008:32(12):1353-8.

67. Ding J-C, Xu G-C, Han R-Z, Ni Y. Biobutanol production from corn stover hydrolysate pretreated with recycled ionic liquid by Clostridium saccharobutylicum DSM 13864. Bioresour Technol. 2016;199:228-34.

68. Li H, Xiong L, Chen X, Wang C, Qi G, Huang C, et al. Enhanced enzymatic hydrolysis and acetone-butanol-ethanol fermentation of sugarcane bagasse by combined diluted acid with oxidate ammonolysis pretreatment. Bioresour Technol. 2017;228:257-63.

69. Yang M, Zhang J, Kuittinen S, Vepsäläinen J, Soininen P, Keinänen M, et al. Enhanced sugar production from pretreated barley straw by additive xylanase and surfactants in enzymatic hydrolysis for acetonebutanol-ethanol fermentation. Bioresour Technol. 2015;189:131-7.

70. Tang C, Chen Y, Liu J, Shen T, Cao Z, Shan J, et al. Sustainable biobutanol production using alkali-catalyzed organosolv pretreated cornstalks. Ind Crops Prod. 2017:95:383-92.

71. Xin F, Wu Y, He J. Simultaneous fermentation of glucose and xylose to butanol by Clostridium species strain $\mathrm{BOH}_{3}$. Appl Environ Microbiol. 2014;80(15):4771-8.

72. Yu L, Xu M, Tang IC, Yang ST. Metabolic engineering of Clostridium tyrobutyricum for n-butanol production through co-utilization of glucose and xylose. Biotechnol Bioeng. 2015;112(10):2134-41.

73. Boonsombuti A, Komolpis K, Luengnaruemitchai A, Wongkasemjit S. Enhancement of $A B E$ fermentation through regulation of ammonium acetate and D-xylose uptake from acid-pretreated corncobs. Ann Microbiol. 2014;64(2):431-9.

74. Jørgensen $\mathrm{H}$, Kristensen JB, Felby C. Enzymatic conversion of lignocellulose into fermentable sugars: challenges and opportunities. Biofuels Bioprod Biorefin. 2007;1(2):119-34.

75. Ezeji T, Qureshi N, Blaschek HP. Production of acetone-butanol-ethanol (ABE) in a continuous flow bioreactor using degermed corn and Clostridium beijerinckii. Process Biochem. 2007;42(1):34-9.

76. Pienkos PT, Zhang M. Role of pretreatment and conditioning processes on toxicity of lignocellulosic biomass hydrolysates. Cellulose. 2009:16(4):743-62.

77. Sun Y, Jin Y, Gao X, Li X, Xiao Y, Yao Z. Effects of byproducts from acid hydrolysis of lignocelluloses on butanol fermentation by Clostridium acetobutylicum CICC8012. Chin J Appl Environ Biol. 2010;16(6):845-50.

78. Wang S, Zhang Y, Dong H, Mao S, Zhu Y, Wang R, et al. Formic acid triggers the "acid crash" of acetone-butanol-ethanol fermentation of Clostridium acetobutylicum. Appl Environ Microbiol. 2011;77(5):1674-80.

79. Maddox I, Steiner E, Hirsch S, Wessner S, Gutierrez N, Gapes J, et al. The cause of "acid crash" and "acidogenic fermentations" during the batch acetone-butanol-ethanol (ABE-) fermentation process. J Mol Microbiol Biotechnol. 2000;2(1):95-100.

80. Terracciano JS, Kashket ER. Intracellular conditions required for initiation of solvent production by Clostridium acetobutylicum. Appl Environ Microbiol. 1986;52(1):86-91.

81. Lee SY, Park JH, Jang SH, Nielsen LK, Kim J, Jung KS. Fermentative butanol production by Clostridia. Biotechnol Bioeng. 2008;101(2):209-28.

82. $\mathrm{He} \mathrm{Q}$, Chen $\mathrm{H}$. Improved efficiency of butanol production by absorbed lignocellulose fermentation. J Biosci Bioeng. 2013;115(3):298-302.

83. Qureshi N, Annous BA, Ezeji TC, Karcher P, Maddox IS. Biofilm reactors for industrial bioconversion processes: employing potential of enhanced reaction rates. Microb Cell Fact. 2005;4(1):24.

84. Li S-Y, Srivastava R, Suib SL, Li Y, Parnas RS. Performance of batch, fedbatch, and continuous A-B-E fermentation with $\mathrm{pH}$-control. Bioresour Technol. 2011;102(5):4241-50.

85. Ezeji T, Qureshi N, Blaschek H. Acetone butanol ethanol (ABE) production from concentrated substrate: reduction in substrate inhibition by fed-batch technique and product inhibition by gas stripping. Appl Microbiol Biotechnol. 2004;63(6):653-8.

86. Lu C, Dong J, Yang S-T. Butanol production from wood pulping hydrolysate in an integrated fermentation-gas stripping process. Bioresour Technol. 2013;143:467-75.

87. Sun Z. The design and technology of acetone-butanol continuous fermentation. Ind Microbiol. 1981;11:31-7.

88. Qureshi N, Lai L, Blaschek H. Scale-up of a high productivity continuous biofilm reactor to produce butanol by adsorbed cells of Clostridium beijerinckii. Food Bioprod Process. 2004;82(2):164-73.

89. Huang W-C, Ramey DE, Yang S-T, editors. Continuous production of butanol by Clostridium acetobutylicum immobilized in a fibrous bed bioreactor. In: Proceedings of the twenty-fifth symposium on biotechnology for fuels and chemicals held May 4-7, 2003, in Breckenridge, CO. Springer: New York; 2004.

90. Tashiro Y, Takeda K, Kobayashi G, Sonomoto K, Ishizaki A, Yoshino S. High butanol production by Clostridium saccharoperbutylacetonicum N1-4 in fed-batch culture with pH-stat continuous butyric acid and glucose feeding method. J Biosci Bioeng. 2004;98(4):263-8. 
91. Jang YS, Malaviya A, Lee SY. Acetone-butanol-ethanol production with high productivity using Clostridium acetobutylicum BKM19. Biotechnol Bioeng. 2013;110(6):1646-53.

92. Jiang Y, Xu C, Dong F, Yang Y, Jiang W, Yang S. Disruption of the acetoacetate decarboxylase gene in solvent-producing Clostridium acetobutylicum increases the butanol ratio. Metab Eng. 2009;11(4-5):284-91.

93. Xiao H, Gu Y, Ning Y, Yang Y, Mitchell WJ, Jiang W, et al. Confirmation and elimination of xylose metabolism bottlenecks in glucose phosphoenolpyruvate-dependent phosphotransferase system-deficient Clostridium acetobutylicum for simultaneous utilization of glucose, xylose, and arabinose. Appl Environ Microbiol. 2011;77(22):7886-95.

94. Ren C, Gu Y, Hu S, Wu Y, Wang P, Yang Y, et al. Identification and inactivation of pleiotropic regulator $C \mathrm{cpA}$ to eliminate glucose repression of xylose utilization in Clostridium acetobutylicum. Metab Eng. 2010;12(5):446-54.

95. Heo M-J, Jung H-M, Um J, Lee S-W, Oh M-K. Controlling citrate synthase expression by CRISPR/Cas9 genome editing for $n$-butanol production in Escherichia coli. ACS Synth Biol. 2016;6(2):182-9.

96. Wang Y, Zhang Z-T, Seo S-O, Choi K, Lu T, Jin Y-S, et al. Markerless chromosomal gene deletion in Clostridium beijerinckii using CRISPR/Cas9 system. J Biotechnol. 2015;200:1-5.

97. Jiang Y, Guo D, Lu J, Dürre P, Dong W, Yan W, et al. Consolidated bioprocessing of butanol production from xylan by a thermophilic and butanologenic Thermoanaerobacterium sp. M5. Biotechnol Biofuels. 2018;11(1):89.

98. Ounine K, Petitdemange H, Raval G, Gay R. Acetone-butanol production from pentoses by Clostridium acetobutylicum. Biotechnol Lett. 1983;5(9):605-10.

99. Fond O, Engasser JM, Matta-El-Amouri G, Petitdemange $H$. The acetone butanol fermentation on glucose and xylose. I. Regulation and kinetics in batch cultures. Biotechnol Bioeng. 1986;28(2):160-6.

100. GuY, Ding Y, Ren C, Sun Z, Rodionov DA, Zhang W, et al. Reconstruction of xylose utilization pathway and regulons in Firmicutes. BMC Genom. 2010;11(1):255

101. Nölling J, Breton G, Omelchenko MV, Makarova KS, Zeng Q, Gibson $\mathrm{R}$, et al. Genome sequence and comparative analysis of the solvent-producing bacterium Clostridium acetobutylicum. J Bacteriol. 2001;183(16):4823-38

102. Chen Y, Zhou T, Liu D, Li A, Xu S, Liu Q, et al. Production of butanol from glucose and xylose with immobilized cells of Clostridium acetobutylicum. Biotechnol Bioprocess Eng. 2013;18(2):234-41.

103. Jiang W, Wen Z, Wu M, Li H, Yang J, Lin J, et al. The effect of pH control on acetone-butanol-ethanol fermentation by Clostridium acetobutylicum ATCC 824 with xylose and D-glucose and D-xylose mixture. Chin J Chem Eng. 2014;22(8):937-42.

104. Wu Y, Xue C, Chen L, Yuan W, Bai F. Synergistic effect of calcium and zinc on glucose/xylose utilization and butanol tolerance of Clostridium acetobutylicum. FEMS Microbiol Lett. 2016;363(5):fnw023.

105. Shi Y, Li Y-X, Li Y-Y. Large number of phosphotransferase genes in the Clostridium beijerinckii NCIMB 8052 genome and the study on their evolution. BMC Bioinform. 2010;11(11):S9.

106. Poehlein A, Solano JDM, Flitsch SK, Krabben P, Winzer K, Reid SJ, et al. Microbial solvent formation revisited by comparative genome analysis. Biotechnol Biofuels. 2017;10(1):58.

107. Servinsky MD, Kiel JT, Dupuy NF, Sund CJ. Transcriptional analysis of differential carbohydrate utilization by Clostridium acetobutylicum Microbiology. 2010;156(11):3478-91.

108. Rodionov DA, Mironov AA, Gelfand MS. Transcriptional regulation of pentose utilisation systems in the Bacillus/Clostridium group of bacteria. FEMS Microbiol Lett. 2001;205(2):305-14.

109. Grimmler C, Held C, Liebl W, Ehrenreich A. Transcriptional analysis of catabolite repression in Clostridium acetobutylicum growing on mixtures of D-glucose and D-xylose. J Biotechnol. 2010;150(3):315-23.

110. Servinsky M, Germane K, Liu S, Kiel J, Clark A, Shankar J, et al. Arabinose is metabolized via a phosphoketolase pathway in
Clostridium acetobutylicum ATCC 824. J Ind Microbiol Biotechnol. 2012;39(12):1859-67.

111. Liu L, Zhang L, Tang W, Gu Y, Hua Q, Yang S, et al. Phosphoketolase pathway for xylose catabolism in Clostridium acetobutylicum revealed by 13C-metabolic flux analysis. J Bacteriol. 2012;194(19):5413-22.

112. Zhang L, Leyn SA, Gu Y, Jiang W, Rodionov DA, Yang C. Ribulokinase and transcriptional regulation of arabinose metabolism in Clostridium acetobutylicum. J Bacteriol. 2011;194(5):1055-64.

113. Gu Y, Li J, Zhang L, Chen J, Niu L, Yang Y, et al. Improvement of xylose utilization in Clostridium acetobutylicum via expression of the talA gene encoding transaldolase from Escherichia coli. J Biotechnol. 2009;143(4):284-7.

114. Xiao H, Li Z, Jiang Y, Yang Y, Jiang W, Gu Y, et al. Metabolic engineering of D-xylose pathway in Clostridium beijerinckii to optimize solvent production from xylose mother liquid. Metab Eng. 2012;14(5):569-78.

115. Birgen C, Markussen S, Wentzel A, Preisig HA. The effect of feeding strategy on butanol production by Clostridium beijerinckii NCIMB 8052 using glucose and xylose. Chem Eng Trans. 2018;65:283-8.

116. Ounine K, Petitdemange H, Raval G, Gay R. Regulation and butanol inhibition of D-xylose and D-glucose uptake in Clostridium acetobutylicum. Appl Environ Microbiol. 1985;49(4):874-8.

117. Wayman M, Yu S. Acetone-butanol fermentation of xylose and sugar mixtures. Biotechnol Lett. 1985;7(4):255-60.

118. Noguchi T, Tashiro Y, Yoshida T, Zheng J, Sakai K, Sonomoto K. Efficient butanol production without carbon catabolite repression from mixed sugars with Clostridium saccharoperbutylacetonicum N1-4. J Biosci Bioeng. 2013;116(6):716-21.

119. El Kanouni A, Zerdani I, Zaafa S, Znassni M, Loutfi M, Boudouma M. The improvement of glucose/xylose fermentation by Clostridium acetobutylicum using calcium carbonate. World J Microbiol Biotechnol. 1998;14(3):431-5.

120. Magalhães BL, Grassi MCB, Pereira GA, Brocchi M. Improved n-butanol production from lignocellulosic hydrolysate by Clostridium strain screening and culture-medium optimization. Biomass Bioenergy. 2018;108:157-66.

121. Zhang J, Zhu W, Xu H, Li Y, Hua D, Jin F, et al. Simultaneous glucose and xylose uptake by an acetone/butanol/ethanol producing laboratory Clostridium beijerinckii strain SE-2. Biotechnol Lett. 2016;38(4):611-7.

122. Rohatgi A. WebPlotDigitizer. http://arohatgi.info/WebPlotDigitizer. Accessed June 2018.

123. Tukey JW. Exploratory data analysis: reading. Massachusetts: AddisonWesley; 1977

124. Kim BH, Bellows P, Datta R, Zeikus J. Control of carbon and electron flow in Clostridium acetobutylicum fermentations: utilization of carbon monoxide to inhibit hydrogen production and to enhance butanol yields. Appl Environ Microbiol. 1984;48(4):764-70.

125. Yu H, Khan F, Garaniya V. A sparse PCA for nonlinear fault diagnosis and robust feature discovery of industrial processes. AIChE J. 2016;62(5):1494-513.

126. Croux C, Dehon C. Influence functions of the Spearman and Kendall correlation measures. Stat Methods Appl. 2010;19(4):497-515.

127. Birgen C, Markussen S, Wentzel A, Preisig HA. Response surface methodology for understanding glucose and xylose utilization by Clostridium beijerinckii NCIMB 8052. Chem Eng Trans. 2018;65:61-6.

128. Shinto H, Tashiro Y, Kobayashi G, Sekiguchi T, Hanai T, Kuriya Y, et al. Kinetic study of substrate dependency for higher butanol production in acetone-butanol-ethanol fermentation. Process Biochem. 2008;43(12):1452-61.

\section{Publisher's Note}

Springer Nature remains neutral with regard to jurisdictional claims in published maps and institutional affiliations. 